\title{
Investigations of albumin-insulin detemir complexes using molecular dynamics simulations and free energy calculations
}

\author{
Line A. Ryberga ${ }^{*}$, Pernille Sønderby ${ }^{a}$, Jens T. Bukrinski ${ }^{b}$, Pernille Harris ${ }^{a}$, and Günther H. J. \\ Peters $^{\text {a* }}$ \\ a Department of Chemistry, Technical University of Denmark, 280o Kongens Lyngby, Denmark and ${ }^{\mathrm{b}}$ CMC assist \\ ApS, 2500 Copenhagen, Denmark. \\ KEYWORDS: human serum albumin, insulin detemir, protein-protein complexes, molecular dynamics simulations, \\ dynamic light scattering, small-angle $X$-ray scattering, free energy calculations
}

\begin{abstract}
Insulin detemir is a lipidated insulin analogue that obtains a half-life extension by oligomerization and reversible binding to human serum albumin. In the present study, the complex between a detemir hexamer and albumin is investigated by an integrative approach combining molecular dynamics (MD) simulations, molecular mechanics PoissonBoltzmann surface area (MM-PBSA) free energy calculations and dynamic light scattering (DLS) experiments. Recent reported small angle X-ray scattering data could not unambiguously resolve the exact binding site of detemir on albumin. We therefore applied MD simulations to deduce the binding site and key protein-protein interactions. MD simulations were started from initial complex structures based on the SAXS models and free energies of binding were estimated from the simulations by using the MM-PBSA approach for the different binding positions. The results suggest that the overlapping $\mathrm{FA}_{3}-\mathrm{FA}_{4}$ binding site (named FA4) is the most favorable site with a calculated free energy of binding of $-28 \pm 6$ $\mathrm{kcal} / \mathrm{mol}$ and a good fit to the reported SAXS data throughout the simulations. Multiple salt bridges, hydrogen bonds and favorable van der Waals interactions are observed in the binding interface that promote complexation. The binding to FA4 is further supported by DLS competition experiments with the prototypical FA4 ligand, ibuprofen, showing displacement of detemir by ibuprofen. This study provides information on albumin-detemir binding on a molecular level, which could be utilized in a rational design of future lipidated albumin-binding peptides.
\end{abstract}

\section{INTRODUCTION}

Human serum albumin is the most abundant protein in the circulatory system with a blood plasma concentration of $35-50 \mathrm{mg} / \mathrm{mL}$ and has a half-life of 19 days in the body due to recycling by the neonatal Fc receptor. ${ }^{1}$ The biological function of albumin is manifold, and albumin plays an important role in the regulation of the colloidal osmotic pressure of the blood and in the transport of longchain fatty acids, bilirubin ${ }^{2}$, metal ions, and a great number of therapeutic drugs ${ }^{3-5}$. The pharmacokinetic properties of albumin makes it interesting in a pharmaceutical perspective as a platform for half-life extension of biopharmaceuticals. ${ }^{6}$ One of the major challenges for administering biopharmaceuticals and especially peptidebased drugs is their limited half-lives due to enzymatic degradation and clearance in the body by renal filtration. ${ }^{7}$ To overcome these shortcomings, one successful route is the covalent or non-covalent association to albumin, and hence, albumin has emerged as a versatile protein used in drug delivery of biopharmaceuticals. Lipidation is a successful strategy to obtain non-covalent albumin association that utilize albumin's natural affinity for fatty acids. Multiple products using this principle are available on the market, ${ }^{8,9}$ for instance the insulin analogues, insulin detemir and insulin degludec, and the glucagon-like peptide 1 analogues, liraglutide and semaglutide. Apart from leading to albumin association, lipidation of the peptide-based drugs also leads to self-association, which additionally prolongs their half-lives. Although the selfassociation properties of the insulin analogues ${ }^{10-16}$ and liraglutide ${ }^{17}$ are well studied, their association to albumin has not been fully explored and hence, a molecular understanding of the complex formation has not been established. The focus of this study is on detemir's association to albumin.

While the albumin-detemir binding has been the topic of other studies, there is yet no consensus on the correct binding site. Kurtzhals et al. ${ }^{18}$ studied the binding between albumin and detemir and found that long chain fatty acids $(>12 \mathrm{C}$ ) displace detemir to a higher extent than octanoate, suggesting that detemir binds to a fatty acid binding site with preference for longer fatty acids. Kjeldsen et al.19 studied the interactions between detemir and the individual albumin domains I and III. The authors concluded that detemir binds to domain III and only weakly to domain I. Performing spectrofluorophotometric studies in combination with molecular docking, Fatima et 
al. ${ }^{20}$ proposed that detemir binds to albumin in-between domain I and III. The binding stoichiometry between albumin and detemir was studied by Havelund et al. in $2004^{21}$, and it was found that albumin binds to both dimeric and hexameric detemir.

Recently, small-angle X-ray scattering (SAXS) solution structures of albumin-detemir/degludec complexes in 1:6, 1:12, and 2:12 (albumin:insulin analogue) stoichiometries were presented $^{22}$. Due to the limited resolution of SAXS and the symmetric shape of albumin, an exact binding site for the two insulin analogues could not be identified.

To close the gap and to gain a more detailed molecular understanding of the protein-protein interactions, we apply molecular dynamics (MD) simulations on complexes between albumin and a detemir hexamer. MD simulations and docking methodologies have been used previously to provide a molecular explanation of experimental results on albumin and insulin alone. Computational studies on insulin and insulin analogues have for instance investigated the dimerization pathway of the peptides, ${ }^{23,24}$ the effect of mutations on protein stability and potency, ${ }^{25,26,27}$ interactions with excipients at different physicochemical conditions, ${ }^{28,29}$ and the effect of water molecules and hydrogen bond network on peptide stability. ${ }^{30,31}$ The main focus of albumin studies has been albumin's capability to bind potential therapeutic, small organic molecules, 32,33,34 chemical additives, 35 and natural products such as monosaccharides ${ }^{36}$ and flavonoids 37 to determine binding poses of the ligands, binding free energy of the ligands and key interactions between albumin and the ligands. Albumin-ligand and albumin-ion interactions have also been studied in different physicochemical conditions. ${ }^{38,39}$ Possible conformational changes on binding of fatty acids to albumin have been observed through MD simulations, 40 high- and lowaffinity fatty acid binding sites on albumin have been identified based on binding free energy calculations and the pathway for the binding process of fatty acids to the highest affinity binding site has been reported.41 Furthermore, studies have been performed to study the interactions of albumin with other biomolecules such as Interferon $\alpha^{-1} b^{42}$ and polyamidoamine dendrimers ${ }^{43}$ for drug delivery purposes and peptides to modulate proteinprotein interactions. ${ }^{44}$ Albumin flexibility has been studied using principal component analysis of the dynamics of subdomains revealing that conformational protein flexibility favorable precede ligand complexation and that ligand binding can induce allosteric effects to other binding sites. 45 These studies emphasize the important role of computational tools to complement experimental studies and to provide the necessary molecular understanding.

As mentioned above, our computational study focusses on albumin-detemir interactions. We used the molecular mechanics Poisson-Boltzmann surface area (MM-PBSA) approach to rank different binding positions and in combination with SAXS data to identify the most structurally and energetic favorable binding site and key residues involved in protein-protein interactions. MM-
PBSA is an attractive method, since it is computationally less expensive than other more advanced types of free energy calculations such as alchemical transformations and potential of mean force ${ }^{46}$. MM-PBSA has previously successfully been used to discriminate between high and low affinity fatty acid binding sites in albumin ${ }^{47}$, as well as ranking of native and non-native poses of protein-protein complexes ${ }^{4}$. Only a limited number of computational protein-insulin studies have been reported. ${ }^{20,49,50}$

To the best of our knowledge, the present work is the first systematic molecular dynamics study on complexes between albumin and a long-acting insulin analogue. The findings in this study can provide an atomic-level description of detemir's binding to albumin and thereby its prolonged action. The knowledge on the albumin-detemir binding could be transferable to other lipidated peptides, and might enable a more rational design of lipidated albumin-binding peptides in the future.

\section{MATERIALS AND METHODS}

\section{Molecular dynamics simulations \\ Construction of systems}

Initial protein coordinates for detemir (PDB entry: ${ }_{1 X D A}{ }^{11}$, chain A-D) and for albumin (PDB entry: ${ }_{1} \mathrm{BJ} 5^{5^{2}}$ ) were obtained from the Protein Data Bank (PDB). Albumin consists of three homologous domains that are asymmetrically assembled (Figure $1 \mathrm{~A}$ ). In the structure, seven common binding sites have been identified for medium- and long-chain fatty acids: FA1-FA 733 (Figure $1 B$ ). Coordinates of the fatty acid chains in 1XDA (HETATM entries MYR) were combined with the coordinates of the acylated lysines (ATOM entries LYS) to common acylated lysine residues, hereafter referred to as Aly. PyMOL (version 1.8.2.3, Schrödinger, LLC) was used for building missing residues, and applying symmetry operations to form the detemir hexamer.

Four albumin-hexamer complexes with binding in respectively $\mathrm{FA}_{1}, \mathrm{FA}_{3}-\mathrm{FA}_{4}$, $\mathrm{FA6}$, and $\mathrm{FA}_{7}$ were generated as described in the Results section, MD simulations. As the binding sites $\mathrm{FA}_{3}$ and $\mathrm{FA}_{4}$ are overlapping (Figure ${ }_{1} \mathrm{~A}$ ), they were treated as one binding site and named FA4 throughout the article. The initial structures for the simulations are shown in Figure $1 \mathrm{C}-\mathrm{F}$. Prior to the simulations of the complexes, the hexamer was simulated alone. From that simulation, a hexamer conformation was extracted, in which one Aly fatty acid chain protrudes from the hexamer. This conformation was used for building the complexes. All ligands originally present in the crystal structures were kept in the simulations $\left(\mathrm{Zn}^{2+}\right.$, phenol, and myristates), except for the myristates that would compete with detemir binding in the complexes. Thus, the FA1 bound myristate was deleted in the FA1 simulations, and the $\mathrm{FA}_{3}$ and $\mathrm{FA}_{4}$ bound myristates were deleted in the FA4 simulations. No myristates were bound to FA6 or FA7 in the albumin crystal structure used for the simulations.

The CHARMM $36^{54^{-56}}$ all-atom force field was used for the simulation (including $\mathrm{Zn}^{2+}$ parameters ${ }^{57}$, and $\mathrm{Na}^{+}$and $\mathrm{Cl}^{-}$parameters $\left.{ }^{8}\right)$. A topology entry for the acylated lysine 

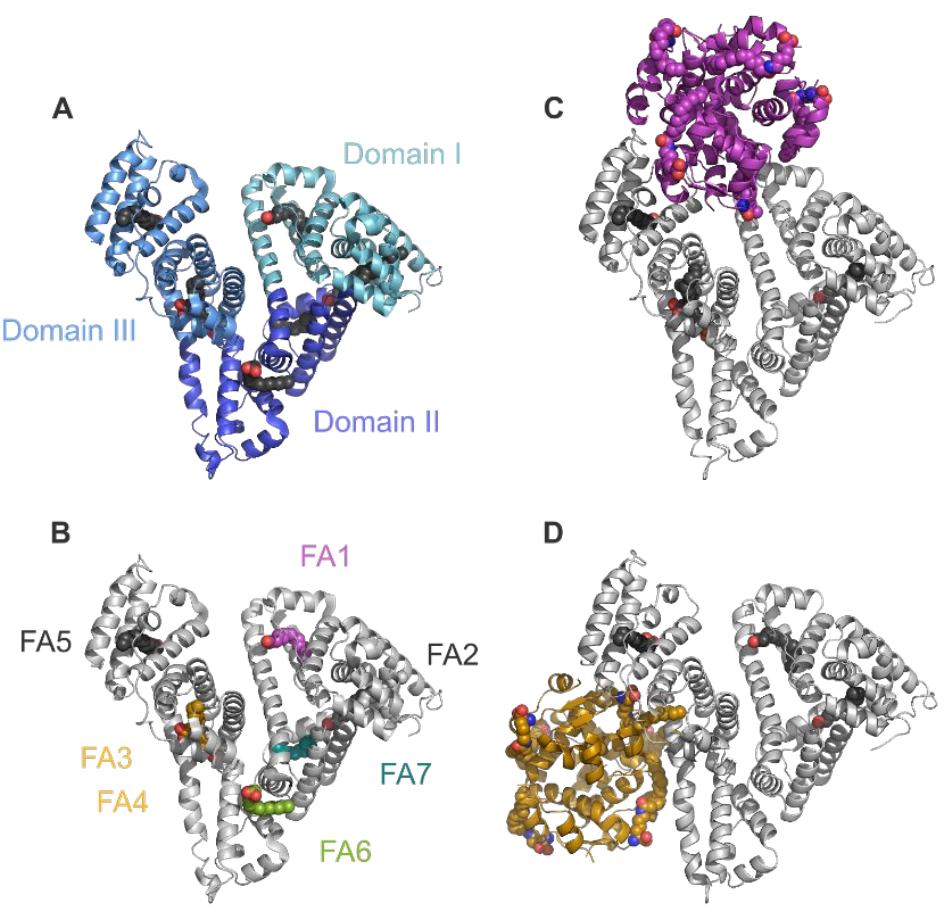

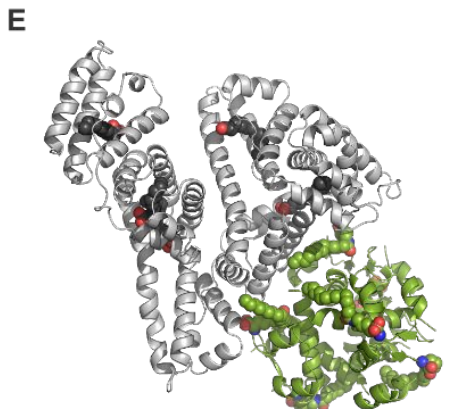

F

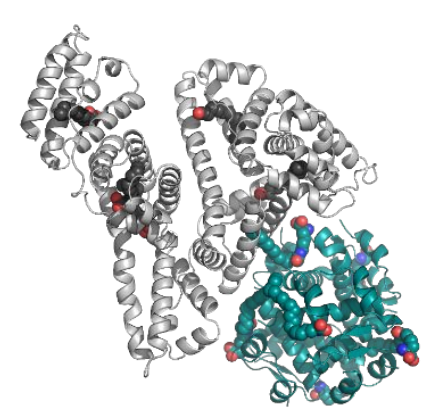

Figure 1. (A) Albumin shown in a cartoon representation colored by domain: turquoise (domain I), purple (domain II), and light blue (domain III). (B) Albumin shown in a grey cartoon representation with myristates bound to FA1-FA7 shown as vdW spheres. The myristates in the binding sites investigated by simulation are colored in magenta $(\mathrm{FAl})$, orange $\left(\mathrm{FA}_{3}\right.$ and $\left.\mathrm{FA} 4\right)$, green (FA6), and blue $\left(\mathrm{FA}_{7}\right)$. Due to the overlap of $\mathrm{FA}_{3}$ and $\mathrm{FA}_{4}$, the two binding sites are considered as one and is for simplicity be named FA4 throughout the article. (C-F) Initial structures of albumin-hexamer complexes with binding in respectively FA1, FA4, FA6, and FA7. The hexamers are colored using the color coding of the myristates in (A). The albumin structure (PDB entry: ${ }_{1} E_{7} \mathrm{G}^{53}$ ) was used in (A-B) to illustrate the seven fatty acid binding sites.

residue was built based on the $\mathrm{CHARMM}_{3} 6$ topology entry for an acetylated lysine and is provided in the supporting information. MolProbity 59,60 was used for determining the protonation states of titratable residues and for flipping sidechains to optimize the hydrogen bond network. The structures were prepared for simulation by the VMD PSFgen Plugin and solvated in a box of TIP $3 \mathrm{P}^{61}$ water molecules with paddings of $10-15 \AA$ using the VMD Solvate Plugin version 1.6. Sodium ions were added to neutralize the systems (18 for detemir hexamer, 15 for albumin and one per myristate bound to albumin) and sodium and chloride ions were added to a concentration of $0.025 \mathrm{M}$, as complex formation between albumin and detemir was observed at this and higher $\mathrm{NaCl}$ concentrations. $^{22}$ The ions were added using the VMD Autoionize Plugin, version 1.3.

\section{Simulation setup}

The simulations were performed with NAMD ${ }^{62}$ version 2.12. The integration time step was set to $2 \mathrm{fs}$. Initially, the systems were minimized using a conjugate gradient algorithm for 1500 steps for the complexes and 500 steps for the albumin and hexamer systems. The simulations were carried out in an NPT ensemble at $310 \mathrm{~K}$ and $1 \mathrm{~atm}$. The Langevin method was applied for temperature control with a damping coefficient of $1 \mathrm{ps}^{-1}$, and the Langevin piston method $^{63}$ was applied for pressure control with a piston period of $100 \mathrm{fs}$ and a piston decay of 50 fs. The neighbor list was updated every 2 fs and set to a distance of 14 A. The short-range van der Waals (vdW) interactions were cut off at $12 \AA$ in combination with a switching function starting at $10 \AA$. The long-range electrostatics were calculated with the particle mesh Ewald method ${ }^{64,65}$ with a 1 Å grid spacing and full electrostatic evaluation every 4 fs. All hydrogen bonds were kept rigid using the SHAKE algorithm ${ }^{66}$. The simulations of the complexes were run in duplicates and each of them for $200 \mathrm{~ns}$. The duplicates were initiated from the same minimized structure but using different seeds for the generation of the initial velocities.

\section{Trajectory analysis}

Root-mean-square deviation (RMSD) was calculated based on backbone atoms ( $\mathrm{C}, \mathrm{O}, \mathrm{N}, \mathrm{CA})$ and were calculated relative to the minimized structures. The fits to experimental SAXS curves were calculated every 2 ns with $C_{\text {CRYSOL }}{ }^{67}$ using 500 points in the theoretical curve and fitting up to $q_{\max }=0.4 \AA^{-1}$ with constant background subtraction and by fitting the effective atomic radius and the contrast of the solvation layer. Based on the RMSDs and CRYSOL fits throughout the trajectories, it was evaluated that the systems were in equilibrium after $100 \mathrm{~ns}$, and the equilibrium analyses described in the following were thus carried out for the last $100 \mathrm{~ns}$. 


\section{Binding free energy calculations}

The MM-PBSA approach was used for estimating binding free energies $\left(\Delta G_{\text {bind }}\right)$ of the protein complexes in order to rank the different binding sites. $\Delta G_{b i n d}$ is calculated as the difference between the free energy of the complex $\left(G^{\text {complex }}\right)$ and the free energies of the unbound proteins $\left(G^{\text {albumin }}\right.$ and $\left.G^{\text {detemir }}\right)$ :

$$
\Delta G_{\text {bind }}=G^{\text {complex }}-G^{\text {albumin }}-G^{\text {detemir }}
$$

In the MM-PBSA approach, the free energy is estimated as a sum of gas-phase and solvation energies:

$$
G=E_{\text {int }}+E_{\text {elec }}+E_{v d W}+G_{p o l}+G_{n p}
$$

$E_{\text {int }}, E_{\text {elec }}$ and $E_{v d W}$, are respectively internal, electrostatic and vdW energy contributions to the gasphase energy. $G_{p o l}$ and $G_{n p}$ are polar and non-polar contributions to the solvation energy, respectively. The gas-phase energies were calculated by NAMD Energy Plugin, version 1.4 in VMD using the same force field parameters as for the MD simulations. $G_{n p}$ was calculated from the solvent accessible surface area (SASA) by the relation: $G_{n p}=\gamma S A S A+\beta$. The empirical constants $\gamma$ and $\beta$ were set to $0.00542 \mathrm{kcal} / \mathrm{mol} / \AA^{2}$ and $0.92 \mathrm{kcal} / \mathrm{mol}$, respectively, as applied in previous studies ${ }^{68,69}$. SASA was calculated using VMD and a probe radius of 1.4 $\AA$. $G_{\text {pol }}$ was calculated using the Adaptive Poisson-Boltzmann Solver ${ }^{70}$ (APBS) for solving the linear Poisson-Boltzmann (PB) equation. The $\mathrm{PDB}_{2} \mathrm{PQR}^{71}$ software was used for generating input files for the APBS calculations. Sørensen et al. found that $G_{p o l}$ calculations using Poisson-Boltzmann solvers are sensitive to input variables, including grid spacing and internal dielectric constant of the protein $\left(\varepsilon_{i n}\right)$. Prior to the MM-PBSA calculations, the grid spacing sensitivity was tested and the optimal grid spacing for the system was found to be $0.4 \AA$ (data not shown), which was used in the calculations. As proteins cannot be considered continuum dielectric media, $\varepsilon_{i n}$ is not a physical constant that can be measured experimentally. Values of $\varepsilon_{\text {in }}$ ranging from 1 to 20 are commonly employed in MM-PBSA studies, and it has been suggested that the optimal value to use is system and method dependent. ${ }^{72-74}$ In an MM-PBSA study of protein complexes, Simões et al. ${ }^{69}$ found better agreement with experimental data using values for $\varepsilon_{\text {in }}$ ranging from 7 to 11 . Based on their study, $\varepsilon_{i n}$ values were tested in this range. The ranking of the binding sites were found to be independent of the chosen $\varepsilon_{i n}$. As the lowest standard deviations were found using $\varepsilon_{i n}=7$, this value was applied in the calculations. The exterior dielectric constant is set to 8o. The gas-phase and non-polar solvation energies were evaluated every $10 \mathrm{ps}$ of the last $100 \mathrm{~ns}$ of simulations thus amounting to 10000 frames. The polar solvation energies were, however, only calculated every 100 ps as the calculations were very computationally demanding. The standard deviations of the energy contributions were estimated by block averaging 75 .
The MM-PBSA calculations were set up using the singletrajectory approach, where the structures of the unbound proteins are extracted from the trajectory of the protein complex, which results in $E_{\text {int }}=0$ in equation 2. The single-trajectory approach has been successfully employed in a benchmark study ${ }^{48}$ in which protein-protein complexes were ranked using MM-PBSA. Entropy contributions to $\Delta G_{b i n d}$ were not considered in this study, as including entropy does not necessarily improve the ranking of relative binding affinities ${ }^{74,76}$ and it was assumed that the different binding sites would contribute equally.

\section{Interface analysis}

Interactions in the albumin-detemir interface were identified by counting albumin and detemir residues that were within $5 \AA$ proximity of each other using an in-house script. The structures were clustered based on contacts between albumin and detemir using the Fraction of Common Contacts Algorithm ${ }^{77}$ with a distance cut-off of 5 $\AA$ And a threshold of 0.75 .

\section{Dynamic light scattering}

Dynamic light scattering (DLS) titration experiments were carried out for albumin-detemir mixtures in a 1:6 molar albumin:detemir ratio. Insulin detemir (detemir) was obtained from Levemir ${ }^{\circledR}$ (Novo Nordisk A/S) and dialyzed into a buffer containing $5 \mathrm{mM} \mathrm{Na}_{2} \mathrm{HPO}_{4}, 15 \mathrm{mM}$ phenol, $13 \mathrm{mM} \mathrm{m}$-cresol, $173 \mathrm{mM}$ glycerol, and $20 \mathrm{mM} \mathrm{NaCl}$ and adjusted with $\mathrm{HCl}$ to $\mathrm{pH}$ 7.4. Recombinant human serum albumin was obtained from Recombumin ${ }^{\circledR}$ Elite (Albumedix Ltd) and dialyzed into a buffer containing 25 $\mathrm{mM} \mathrm{NaH} \mathrm{PO}_{4}$ and $215 \mathrm{mM} \mathrm{NaCl}$ and adjusted with $\mathrm{HCl}$ to $\mathrm{pH}$ 6.5. The proteins were mixed in a 1:6 ratio to a total protein concentration of $3.8 \mathrm{mg} / \mathrm{mL}$ and diluted with detemir's dialysis buffer. The mixtures were equilibrated for two hours at room temperature without stirring. Ibuprofen sodium salt was thereafter added in stoichiometric amounts from 1-25, and the samples were further equilibrated for three hours. After ligand addition, the final protein concentration was $3.2 \mathrm{mg} / \mathrm{mL}$ and the final buffer compositions was $6 \mathrm{mM} \mathrm{Na} \mathrm{HPO}_{4}, 14 \mathrm{mM} \mathrm{m-}$ cresol, $13 \mathrm{mM}$ phenol, $166 \mathrm{mM}$ glycerol, $28 \mathrm{mM} \mathrm{NaCl}$ at $\mathrm{pH}$ 7.4.

The samples were measured in triplicate on a DynaPro DLS plate reader (Wyatt Technology Corporation, Santa Barbara, CA). Wyatt Dynamics software was used for data collection and analysis. The samples were loaded onto 96 well non-binding Corning ${ }^{\circledR}$ microplates and centrifuged for $2 \mathrm{~min}$ at $2000 \mathrm{rpm}$ at room temperature to remove air bubbles. The sample volume was $100 \mu \mathrm{L}$, the temperature was $298 \mathrm{~K}$, and each sample was measured ten times for five seconds. $Z$-averages obtained by cumulants analysis are reported in the results section as hydrodynamic radius $\left(R_{h}\right)$ and have been corrected for viscosities. 


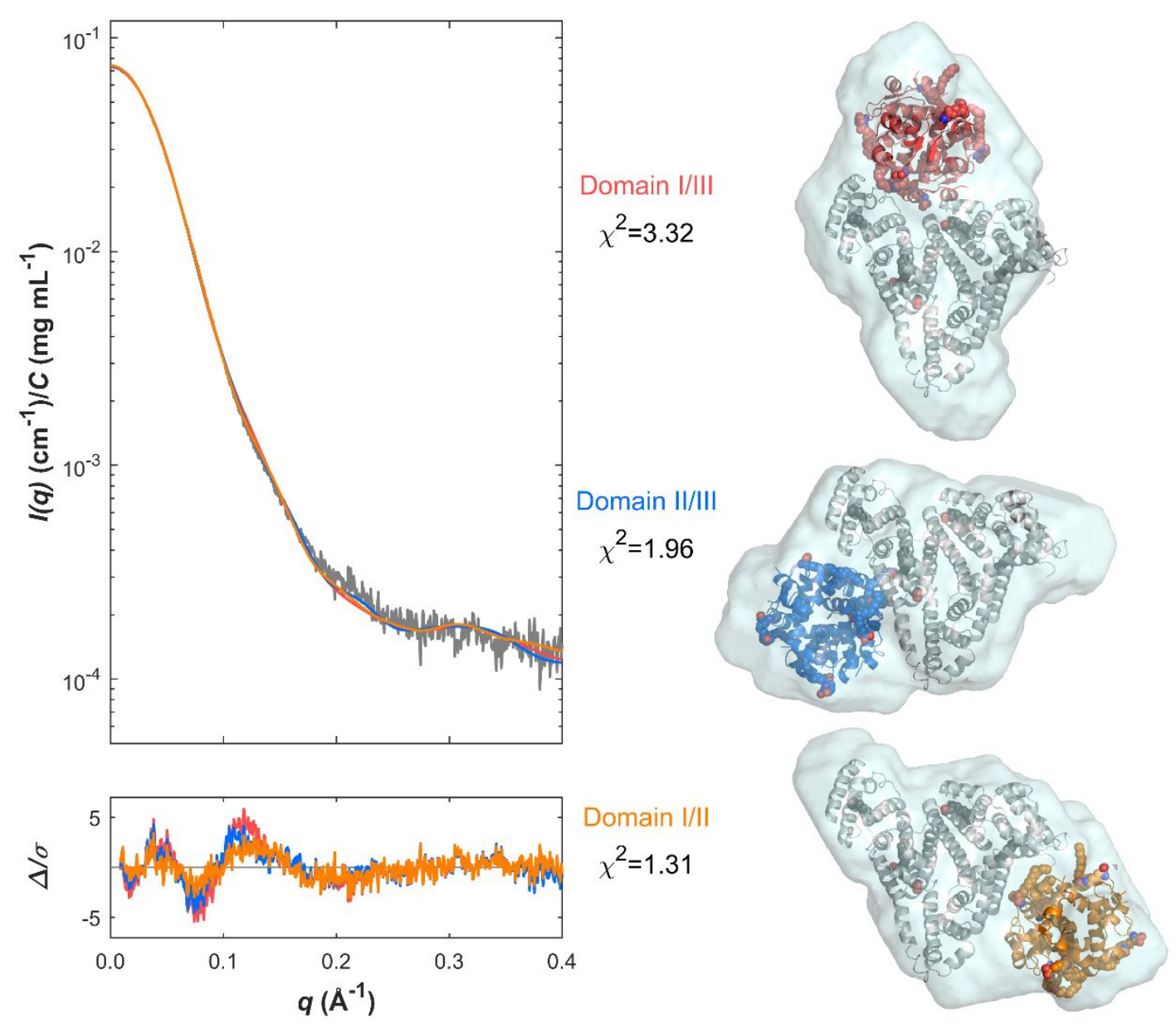

Figure 2. Rigid body modelling of the albumin-detemir hexamer complex gives models with binding at the domain interfaces, domain I/III, domain II/III, and domain I/II. The fits of the models to the experimental data (grey) are shown in respectively red, blue, and orange. The lower inset shows error-weighted residual plots for the model fits. The models are shown with albumin in grey, and the hexamers with same color-coding as in the plots.

\section{Small-angle X-ray scattering}

The SAXS data used for setting up the MD simulations and the $a b$-initio model shown in Figure 2 were previously presented. ${ }^{22}$ The experiments were performed at the I911SAXS beamline ${ }^{78}$ at the MAX IV Laboratory (Lund, Sweden). The experimental details can be found in Table 1 and Table 2 as well as the Materials and methods section in Ryberg et al. 2019.22 SASREFCV79,80(SASREF) was used for rigid body modelling with standard settings for X-ray data and based on data up to $q=0.43 \AA^{-1}$. The input structures were the same albumin and detemir hexamer structures that were used for setting up the simulations.

The $\mathrm{NaCl}$ titration SAXS dataset presented in Supplementary Figure S19 was measured at the $\mathrm{P}_{12}$ BioSAXS beamline ${ }^{81}$ at PETRAIII (DESY, Hamburg, Germany). Data collection parameters are given in Supplementary Table S1. Albumin and detemir were mixed in a $1: 6$ molar ratio, corresponding to $1.8 \mathrm{mg} / \mathrm{mL}$ albumin and $3.3 \mathrm{mg} / \mathrm{mL}$ detemir. The recombinant albumin was obtained from Recombumin ${ }^{\circledR}$ Alpha (Albumedix Ltd). The samples were measured in a buffer consisting of $5 \mathrm{mM}$ $\mathrm{Na}_{2} \mathrm{HPO}_{4}, 15 \mathrm{mM}$ phenol, $13 \mathrm{mM} \mathrm{m}$-cresol, $173 \mathrm{mM}$ glycerol, and $20 \mathrm{mM} \mathrm{NaCl}$ that was adjusted with $\mathrm{HCl}$ to $\mathrm{pH}$ 7.4. The
SAXS sample preparation and data collection were carried out as described in Ryberg et al. 2019. ${ }^{22}$ The samples were titrated with o-10o $\mathrm{mM} \mathrm{NaCl}$.

Data analysis and modelling were carried out using the ATSAS Program Package version 2.8.3 ${ }^{82}$. Guinier analysis was performed on the baseline subtracted SAXS curves using PRIMUSqt ${ }^{83}$. If inter-particle interactions were observed, the curves were truncated at low $q$-values. Volume fractions of the different species in the samples were investigated using OLIGOMER ${ }^{8_{3}}$ with a form factor file that was produced by FFMAKER ${ }^{8} 3$ using CRYSOL with standard settings and 256 points in the theoretical scattering curve. The molar 1:6 stoichiometry was used as a constraint in FFMAKER. The OLIGOMER analysis was carried out up to a maximum scattering vector $q_{\max }=0.4$ $\AA^{-1}$ and with addition of a constant component. The structures used as input were fatty acid free albumin (PDB

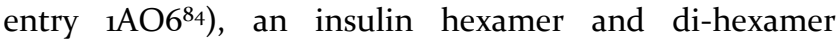
(generated from PDB entry 1TRZ ${ }^{85}$ ). Rigid body models of the insulin tri-hexamer, albumin-hexamer, albumin-dihexamer and albumin-di-hexamer-albumin were taken from the small-angle scattering biological data bank 
$\left(\mathrm{SASBDB}^{86}\right.$ entries SASDEV $^{22}{ }^{22}$ SASDEX $^{22}{ }^{22}$ SASDE$^{2} 6^{22}$ and SASDEY $5^{22}$, respectively.

\section{RESULTS \\ SAXS modelling}

The solution structure of a complex between albumin and a detemir hexamer was modelled using SAXS data in a previous study carried out in our group. The rigid body models of the complex were not conclusive with respect to detemir's binding site on albumin due to the low resolution of the SAXS data and the symmetric shape of albumin. ${ }^{22}$ In the current study, we utilize MD simulations in combination with MM-PBSA calculations to qualify which of the binding site is the most probable site.

Initially, we wanted to identify possible binding positions and carried out rigid body modelling using SASREF. The 22 generated models were clustered into three clusters based on the binding position of the hexamer on albumin. The best fitting model from each cluster and its fit to the data are presented in Figure 2. The models suggest that the hexamer binds at one of the domain interfaces. The fits of the models with binding near domain I/II $\left(\chi^{2}=1.31\right)$ and near domain II/III $\left(\chi^{2}=1.96\right)$ do not differ much considering that conformational changes of the proteins upon binding could be expected. The model with binding near domain I/III model has a slightly worse fit to the data $\left(\chi^{2}=3.32\right)$. The ambiguity of the binding position on albumin can be explained by albumin's triangular shape. With SAXS data alone, it is not possible to distinguish the three sites. We therefore carried out MD simulations to investigate the binding sites on the atomic level.

\section{MD simulations}

The MD simulations were set up based on the rigid body models presented in Figure 2. There is strong evidence ${ }^{87}$ and a general consensus in literature ${ }^{6,18,19,88}$ that detemir binding occurs at a fatty acid binding site as C8-C16 fatty acids and small molecule ligands that bind in albumin's fatty acid binding sites can displace detemir's binding to albumin. ${ }^{18,87}$ Thermodynamic experiments suggest that the albumin-detemir binding is a result of both ionic and hydrophobic interactions between albumin and detemir's acylated lysine residue (Aly) that is also the C-terminal of detemir's B chain. More specifically, the C-terminal carboxylate is predicted to form an ionic bond to a basic residue near one of albumin's binding sites, and the Aly fatty acid chain is predicted to form non-polar interactions with the residues in the binding site. ${ }^{87}$ This information was utilized for setting up the initial structures for the simulations. First of all, by studying the proximity of the binding positions in Figure 2 and the seven common fatty acid binding sites in Figure $1 \mathrm{~B}$, it was evaluated that detemir could bind to FA1, FA4, FA6 or FA7. Secondly, the hexamers in the rigid body models presented in Figure 2 were rotated and translated to position the Aly fatty acid chain at the entry of the fatty acid binding sites while ensuring that the C-terminal carboxylate in proximity to a basic residue. The initial simulation structures are shown in Figure $1 \mathrm{C}-\mathrm{F}$. More detailed views of the binding interfaces are shown in Supplementary Figures $\mathrm{S}_{1}-\mathrm{S}_{4}$.

\section{Trajectory analysis}

The RMSD evolutions of the simulations are presented in Figure 3. For all simulations, there is a steep initial increase in RMSD, which is largely due to conformational changes in the albumin and detemir structures to accommodate the binding (Supplementary Figure $\mathrm{S}_{5}$ ). Apart from the FA6a simulation (Figure $3 \mathrm{C}$ ), the RMSDs stabilize and fluctuate around a constant value after $100 \mathrm{~ns}$ indicating that the simulations have converged. In addition to RMSDs, the fits to the experimental SAXS data throughout the trajectories are calculated and presented in Figure 4. The FA4a, FA4b, and FA7a simulations have the best fits to the experimental data with average $\chi^{2}$ values based on the last $100 \mathrm{~ns}$ of simulations of $2.8 \pm 0.2,2.0 \pm 0.3$, and 2.0 \pm 0.5 , respectively. The FA6 simulations have slightly worse fits to the data and larger fluctuations (average $\chi^{2}$ values of $3 \pm 1$ ). The FAra, FA1b, and FA7b do not fit the data with average $\chi^{2}$ values of $9 \pm 4,6 \pm 1$, and $13 \pm 3$, respectively. Based on the average $\chi^{2}$ values of the duplicates, the FA4 and FA6 simulations fit the data best.
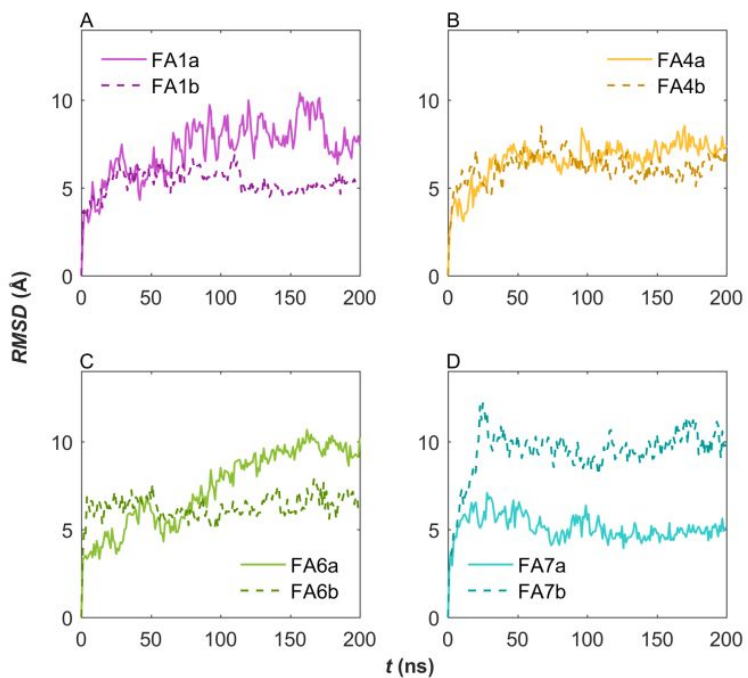

Figure 3. RMSD of backbone atom positions calculated relative to the minimized structures for the (A) FA1, (B) FA4, (C) FA6, and (D) FA7 trajectories. 

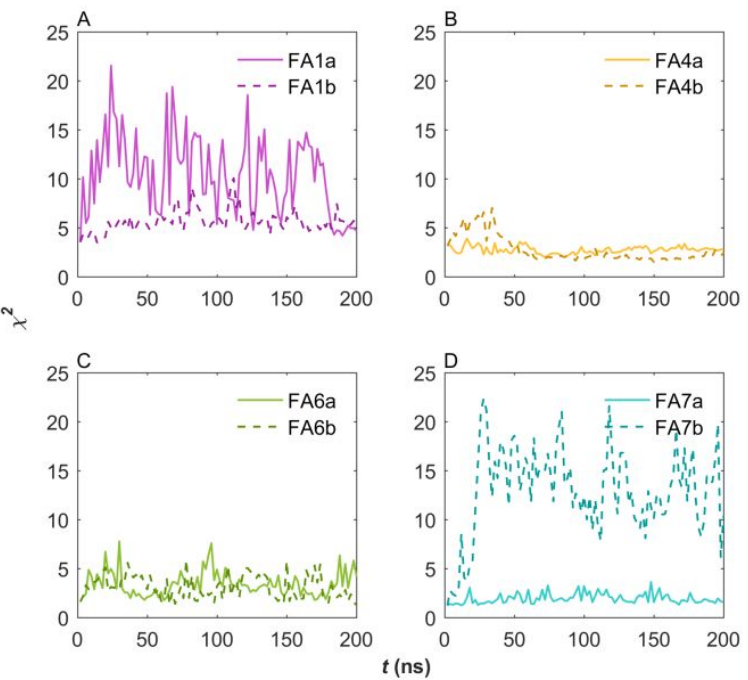

Figure 4. SAXS fits of the complexes calculated by CRYSOL throughout the trajectory.

\section{Binding free energy calculations}

The MM-PBSA approach was used to assess the energetics of the simulations in order to rank the complexes. For all simulations, the electrostatic and vdW energies fluctuate around constant values after $100 \mathrm{~ns}$ of simulations (Supplementary Figures S8 and S9) supporting the conclusion that the simulations have converged. The MM-PBSA calculations were thus carried out for the last 100 ns. The results are presented in Table 1. The FA4 binding site has the most favorable binding energy, $\Delta \bar{G}_{\text {bind }}$ $=-28 \pm 6 \mathrm{kcal} / \mathrm{mol}$, followed by the FAr binding site with $\Delta$ $G_{\text {bind }}=-16 \pm 2 \mathrm{kcal} / \mathrm{mol}$. The FA6 and FA 7 binding sites have the least favorable binding energies with $\Delta \bar{G}_{\text {bind }}=14 \pm 31$ $\mathrm{kcal} / \mathrm{mol}$ and $\Delta \bar{G}_{\text {bind }}=10 \pm 13 \mathrm{kcal} / \mathrm{mol}$, respectively.

Table 1. Binding free energy components of the complexes. The standard deviations are given in parentheses.

\begin{tabular}{|c|c|c|c|c|c|c|c|c|}
\hline & & $\begin{array}{c}\Delta \boldsymbol{E}_{\text {elec }} \\
\mathrm{kcal} / \mathrm{mol}\end{array}$ & $\begin{array}{c}\Delta \boldsymbol{E}_{v d W} \\
\mathrm{kcal} / \mathrm{mol}\end{array}$ & $\begin{array}{c}\Delta \boldsymbol{G}_{\text {pol }} \\
\mathrm{kcal} / \mathrm{mol}\end{array}$ & $\begin{array}{c}\Delta \boldsymbol{G}_{\boldsymbol{n} \boldsymbol{p}} \\
\mathrm{kcal} / \mathrm{mol}\end{array}$ & $\begin{array}{c}\Delta \boldsymbol{E}_{\text {elec }}+\Delta \boldsymbol{G}_{\text {pol }} \\
\mathrm{kcal} / \mathrm{mol}\end{array}$ & $\begin{array}{c}\Delta \boldsymbol{G}_{\boldsymbol{b i n d}^{\mathrm{a}}} \\
\mathrm{kcal} / \mathrm{mol}\end{array}$ & $\begin{array}{c}\Delta \overline{\boldsymbol{G}}_{\text {bind }}{ }^{\mathrm{b}} \\
\mathrm{kcal} / \mathrm{mol}\end{array}$ \\
\hline \multirow{2}{*}{ FA1 } & $\mathrm{a}$ & $-69(1)$ & $-37.2(0.4)$ & $98(2)$ & $-6.0(0.1)$ & $29(2)$ & $-15(2)$ & \multirow{2}{*}{$-16(2)$} \\
\hline & b & $-82(1)$ & $-74.5(0.7)$ & $150.6(0.9)$ & $-11.1(0.1)$ & 68 (1) & $-17(1)$ & \\
\hline \multirow{2}{*}{ FA4 } & $\mathrm{a}$ & $-125.0(0.8)$ & $-68.1(0.6)$ & $172(2)$ & $-11.0(0.1)$ & $47(2)$ & $-32(2)$ & \multirow{2}{*}{$-28(6)$} \\
\hline & b & $-132.9(0.8)$ & $-68.8(0.6)$ & $190(2)$ & $-11.77(0.04)$ & $57(2)$ & $-24(2)$ & \\
\hline \multirow{2}{*}{ FA6 } & a & $48(1)$ & $-46.8(0.4)$ & $41(2)$ & $-7.1(0.1)$ & $89(2)$ & $36(2)$ & \multirow{2}{*}{$14(31)$} \\
\hline & b & $29(1)$ & $-58.5(0.6)$ & $29(1)$ & $-7.4(0.1)$ & $58(1)$ & $-8(1)$ & \\
\hline \multirow{2}{*}{ FA7 } & $\mathrm{a}$ & $17.7(0.9)$ & $-41.3(0.3)$ & $48(2)$ & $-5.7(0.1)$ & $66(2)$ & $19(2)$ & \multirow{2}{*}{$10(13)$} \\
\hline & b & $-8.0(0.9)$ & $-46.3(0.5)$ & $61(1)$ & $-6.7(0.1)$ & $53(2)$ & $0(2)$ & \\
\hline
\end{tabular}

a $\Delta G_{\text {bind }}=\Delta E_{\text {elec }}+\Delta E_{\text {vdW }}+\Delta G_{\text {pol }}+\Delta G_{n p}$

b $\Delta \bar{G}_{b i n d}$ is the average $\Delta G_{b i n d}$ for duplicate simulations with standard deviations given in parentheses.

The MM-PBSA analysis shows that the FA4 complex is

For the FA1 and $\mathrm{FA}_{4}$ complexes, the protein-protein electrostatic energies favor binding. Considering the overall negative charges of albumin and detemir, this indicates that the binding interfaces are complementary. The favorable $\Delta E_{\text {elec }}$ are opposed by unfavorable proteinsolvent $\Delta G_{\text {pol }}$ contributions. In agreement with these observations, $\Delta E_{\text {elec }}$ and $\Delta G_{p o l}$ are often found to partly cancel out ${ }^{68,72}$, as more charged residues in the proteinprotein interface are buried. The desolvation of charged residues consequently leads to less favorable proteinsolvent interactions. However, the total electrostatic contribution to binding $\left(\Delta E_{\text {elec }}+\Delta G_{p o l}\right)$ is sensitive to the definition of the boundary between protein and solvent and the internal dielectric constant, which can lead to an overestimation of the solvation penalty. ${ }^{89,90}$ For all the complexes, the vdW energies favor binding with the most favorable energies for the FA 4 complexes accounting for $\Delta$ $\bar{E}_{v d W}=-68.5 \pm 0.5 \mathrm{kcal} / \mathrm{mol}$. the most favorable binding site, which is in accordance with its good fit to the SAXS data.

\section{Interface analysis}

In the following, we examine the protein-protein interfaces of the complexes. As natural insulin does not bind to albumin ${ }^{21}$, it is expected that the Aly residue promotes binding of detemir to albumin in a manner similar to fatty acid binding. ${ }^{19}$

The frequencies of interfacial residue pairs and representative structures of the complexes are shown in Figure 5 (for the $\mathrm{FA}_{4} \mathrm{~b}$ complex) and Supplementary Figures S1o-S16 (for the remaining complexes). From the heatmaps, it is seen that the Aly residues have more interactions with albumin in the FA4 complexes compared to the other complexes. This is summarized in

Table 2. The FA4 complexes form in average 36 Alyalbumin contacts, which can be linked to their favorable vdW energies (Table 1). In comparison, the FAra and FA7b complexes have the fewest Aly-albumin contacts, which is 
also reflected in their relatively larger radii of gyration $\left(R_{g}\right.$ s) and center-of-mass (COM) distances (Supplementary Figures $\mathrm{S} 6$ and $\mathrm{S}_{7}$, respectively). This supports further the notion that $\mathrm{FA}_{4}$ is the most favorable binding site.

In the FA4 complexes, the Aly residues in chain $\mathrm{D}$ and $\mathrm{H}$ (Figure $5 \mathrm{C}$; $\mathrm{Aly}^{\mathrm{D} 29}$ and $\mathrm{Aly}^{\mathrm{H} 29}$, respectively) account for the majority of the Aly-albumin proximities (Table 2). The specific Aly-albumin residue pairs are highlighted in the heat maps in Figure $5 \mathrm{~A}$ and Supplementary Figure S12A.

$\mathrm{A}$ zoom in on the $\mathrm{Aly}^{\mathrm{D} 29}$ and $\mathrm{Aly}^{\mathrm{H} 29}$ binding sites are shown in Figure 6 for the FA4b simulation and in Supplementary Figure $\mathrm{S}_{17}$ for the FA4a simulation. In both simulations, Aly ${ }^{\mathrm{D} 29}$ protrudes into the hydrophobic cleft of the $\mathrm{FA}_{4}$ binding site and $\mathrm{Aly}^{\mathrm{H}_{2} 9}$ is positioned in the albumin-detemir interface. Salt bridges are observed between $\mathrm{Glu}^{\mathrm{C}} 4$-Lys ${ }^{414}$ (notation: detemir residue-albumin residue), $\mathrm{Glu}^{\mathrm{C} 4-\mathrm{Arg}^{410}}{ }^{2}, \mathrm{Aly}^{\mathrm{D} 29}-\mathrm{Arg}^{410}, \mathrm{Aly}^{\mathrm{H} 29}{ }^{-L_{y s}{ }^{372}}$ and hydrogen bonds are observed between $\mathrm{Phe}^{\mathrm{D}_{1}}-\mathrm{Glu}^{393}$ and

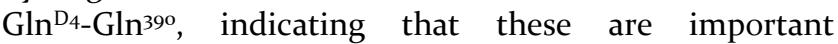

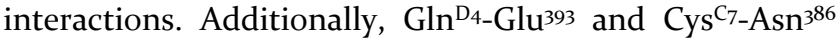
interactions are observed in the FA4a complex, and $\mathrm{Glu}^{\mathrm{B} 21}$ $\mathrm{Lys}^{541}$, Gly ${ }^{\mathrm{C}}-\mathrm{Glu}^{49^{2}}$ and $\mathrm{Glu}^{\mathrm{G}} 4-\mathrm{Lys}^{378}$ are present in the FA4b complex. Based on the heatmaps (Figure $5 \mathrm{~A}$ and Supplementary Figure S12A), Aly ${ }^{\mathrm{D} 29}$ forms favorable vdW interactions with the hydrophobic/aromatic residues in the FA4 binding site: $\mathrm{Leu}^{387}$, Leu ${ }^{394}$, $\mathrm{Phe}^{403}$, $\mathrm{Leu}^{407}$, Tyr ${ }^{411}$, $\mathrm{Leu}^{430}, \mathrm{Leu}^{453}, \mathrm{Phe}^{488}$. In conclusion, $\mathrm{Aly}^{\mathrm{D} 29}$ in the FA4 complexes bind to an albumin fatty acid binding site by a combination of electrostatic and hydrophobic interactions, as expected from literature. ${ }^{87}$

Apart from the FA4 complexes, only in the FA6b complex the Aly residue protrudes into the FA6 binding site. However, the binding energy is noticeably less compared to the one observed for the FA4 complexes indicating that this is not a primary binding site (Table 1). 
B

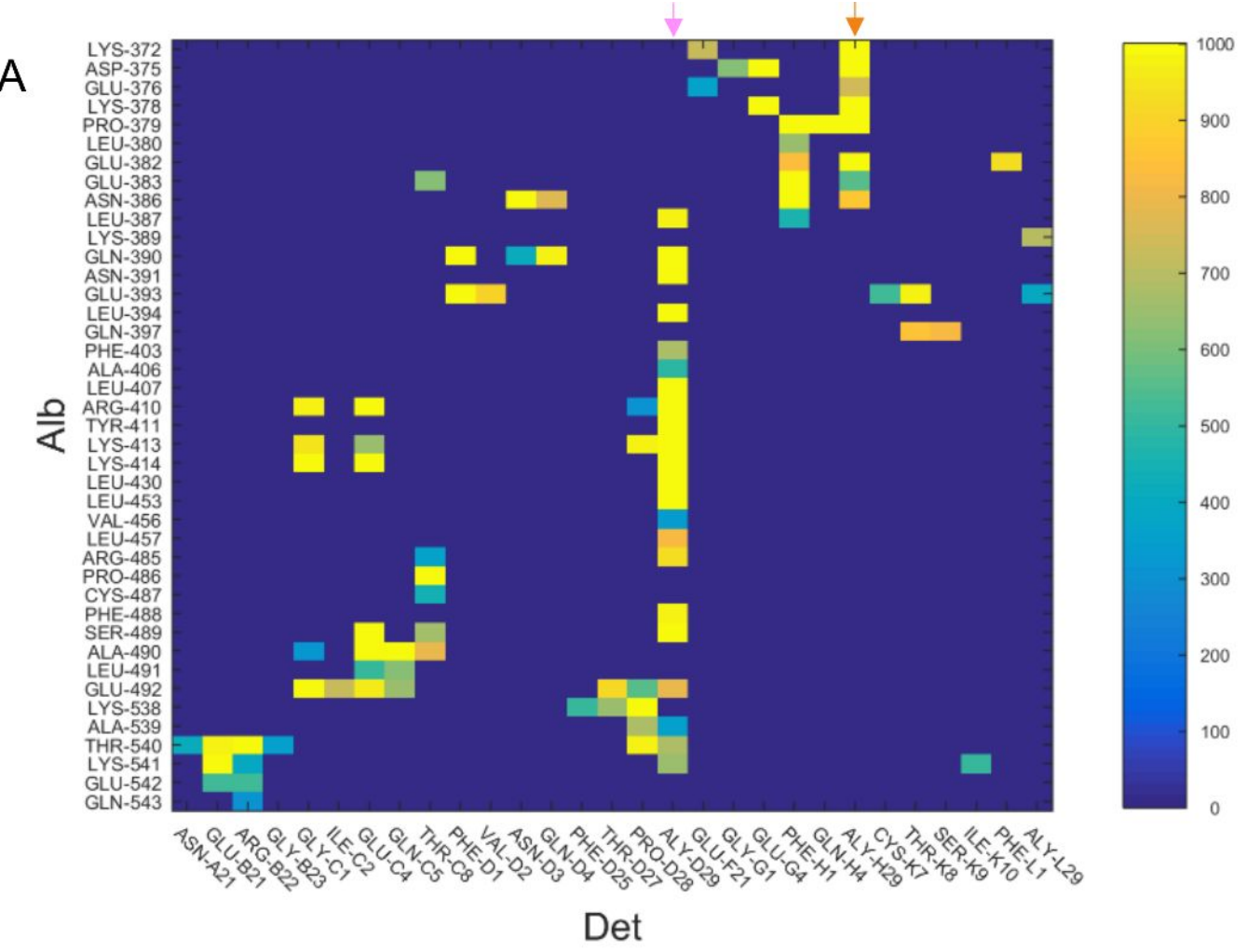

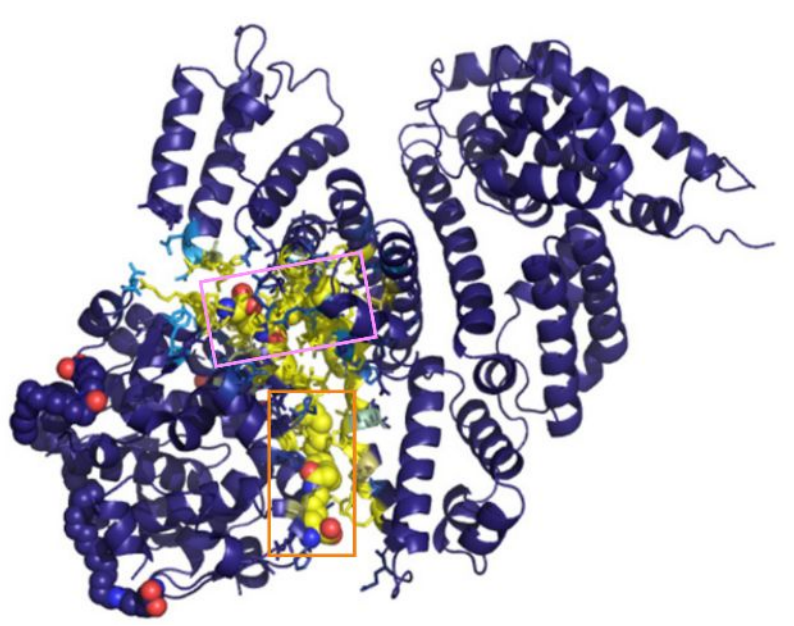

C

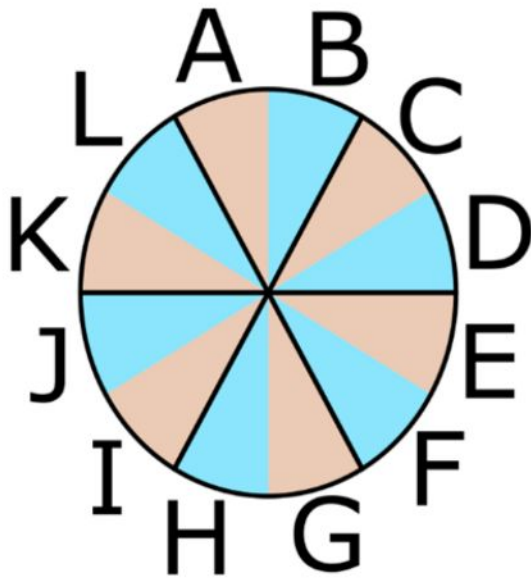

Figure 5. Analysis of interactions in the FA4b simulation. (A) Interaction heatmap of the albumin-detemir interface with albumin residues on the $y$-axis, and detemir residues on the $x$-axis. The color scale goes from blue indicating that the residues are not within $5 \AA$ of each other throughout the simulation to yellow that indicates that the residues are within $5 \AA$ of each other in all simulation frames. The arrows in light pink and orange mark the fatty acid residues present in the binding interface, Aly ${ }^{\mathrm{D} 29}$ and Aly ${ }^{\mathrm{H} 29}$, respectively. (B) The representative structure of the FA4b complex shown as cartoon with Aly residues shown as vdW spheres. The residues are colored according to their maximum interaction values from the heatmap in (A). The Alys located at the interface are marked with rectangles. (C) Schematic overview over chain IDs in a detemir hexamer. Each monomer consists of two chains: chain A shown in grey and chain B shown in light blue. 


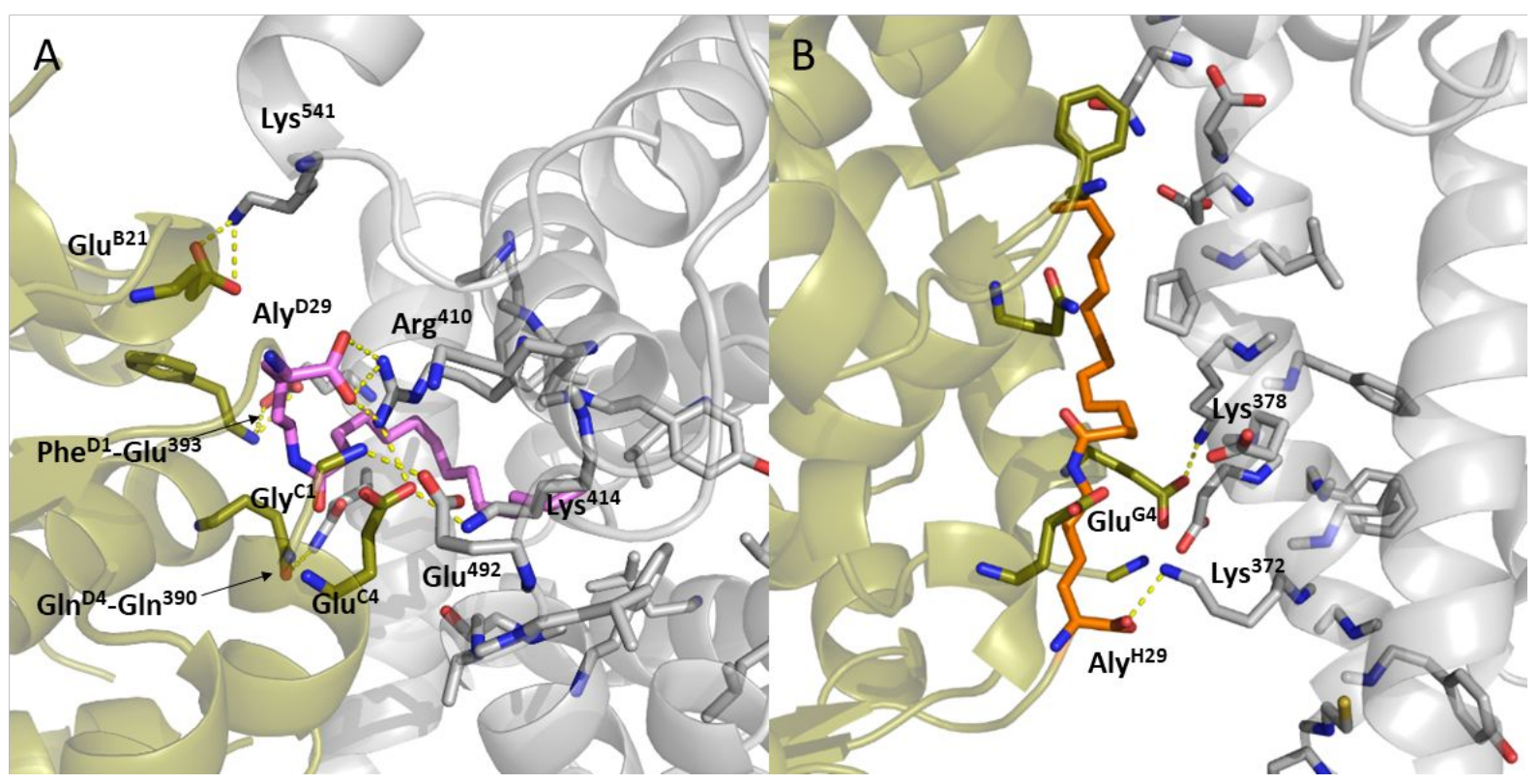

Figure 6. Analysis of interface in the FA4b simulation. (A) and (B) show the interacting residues around Aly ${ }^{\mathrm{D} 29}$ (light pink) and $\mathrm{Aly}^{\mathrm{H} 29}$ (orange), respectively. The detemir hexamer is colored green, and albumin is colored grey.

Table 2. Overview over the number Aly-albumin proximities present in more than $30 \%$ of the last 100 ns of simulation for $\mathrm{Aly}^{\mathrm{D} 29}$, Aly ${ }^{\mathrm{H} 29}$, and $\mathrm{Aly}^{\mathrm{L} 29}$.

\begin{tabular}{ccccc}
\hline & Aly $^{\text {D29 }}$ & Aly $^{\text {H29 }}$ & Aly $^{\text {L29 }}$ & Total \\
\hline FA1a & 7 & 0 & 0 & 7 \\
FA1b & 11 & 6 & 8 & 25 \\
FA4a & 17 & 12 & 0 & 39 \\
FA4b & 22 & 8 & 2 & 32 \\
FA6a & 10 & 5 & 0 & 15 \\
FA6b & 21 & 0 & 1 & 22 \\
FA7a & 11 & 8 & 0 & 19 \\
FA7b & 0 & 8 & 0 & 8 \\
\hline
\end{tabular}

\section{DLS}

From the previous results, FA4 seems to be the most favorable binding site. To test this experimentally, DLS competition experiments were set up. Albumin and detemir were mixed in a 1:6 ratio and titrated with the prototypical $\mathrm{FA}_{4}$ ligand ibuprofen. ${ }^{91-93}$ The results are presented in Figure 7. With the addition of one equivalent of ibuprofen, we observe a decrease in $R_{h}$ corresponding to dissociation of the albumin-hexamer complex. From one to 25 equivalents, $R_{h}$ steadily decreases with a less steep slope compared to the slope when only one equivalent of ibuprofen is added.

In Figure 8, the binding of ibuprofen to $\mathrm{FA}_{4}$ is compared with detemir's binding in the FA4b simulation in order to explain the DLS results on a molecular level. Figure $8 \mathrm{~B}$ and D show the important interactions between ibuprofen's carboxylic acid group and albumin: a salt bridge with Arg ${ }^{410}$ and hydrogen bonds to $\mathrm{Tyr}^{410}$ and $\mathrm{Ser}^{489}$. Figure $8 \mathrm{~A}$ and $\mathrm{C}$ show that $\mathrm{Aly}^{\mathrm{D} 29}$ competes for the same binding site as ibuprofen. While Aly does not form specific interactions with $\operatorname{Ser}^{489}$, the salt bridge to $\operatorname{Arg}^{410}$ is a key interaction for the binding as also illustrated in Figure 6A. Furthermore, hydrophobic interactions of the fatty acid chain are observed with $\mathrm{Phe}^{488}$ and $\mathrm{Ty}^{4{ }^{41}}$. The displacement of detemir with ibuprofen can thus provide further evidence that $\mathrm{FA}_{4}$ is the most favorable binding site.

\section{DISCUSSION}

MD simulations of albumin-detemir complexes with binding in $\mathrm{FA}_{1}, \mathrm{FA} 4, \mathrm{FA} 6$, and $\mathrm{FA}_{7}$ were performed to deduce which is the most favorable binding site. The FA1 and $\mathrm{FA}_{7}$ simulations show greater variabilities within the duplicates in the time evolution of RMSD, $R_{g}$ and COM distance (Figure 3, Supplementary Figures S6 and $\mathrm{S}_{7}$, respectively), whereas the progress of the $\mathrm{FA}_{4}$ simulations is similar for the duplicate simulations. The large fluctuations observed for the FAra simulation can be explained on the molecular level by the hexamer loosing and regaining contact with albumin's domain III. Similarly, the hexamer in the FA7b complex loses contact with albumin's domain I in the beginning of the simulation. When the hexamer is not in contact with the respective 
domains, the complex becomes too large to fit the SAXS data (Figure 4), which is also reflected in the RMSD, $R_{g}$ and COM plots (Figure 3, Supplementary Figures S6 and $\mathrm{S}_{7}$, respectively). In contrast, the FA4 and FA6 complexes have the best fits to the SAXS data, which could indicate that these are the correct binding sites, if only the SAXS fits were considered. When also taking the MM-PBSA energetics of the complexes into account, it is clear that the FA6 binding site $\left(\Delta \bar{G}_{b i n d}=14 \pm 31 \mathrm{kcal} / \mathrm{mol}\right)$ is less favorable than the FA4 site $\left(\Delta \bar{G}_{b i n d}=-28 \pm 6 \mathrm{kcal} / \mathrm{mol}\right)$. According to the MM-PBSA ranking, $\mathrm{FA}_{4}$ is the most favorable binding site followed by $F A 1$, and the equally unfavorable binding sites, FA6 and FA7. The ranking suggests that FA1 could be a secondary

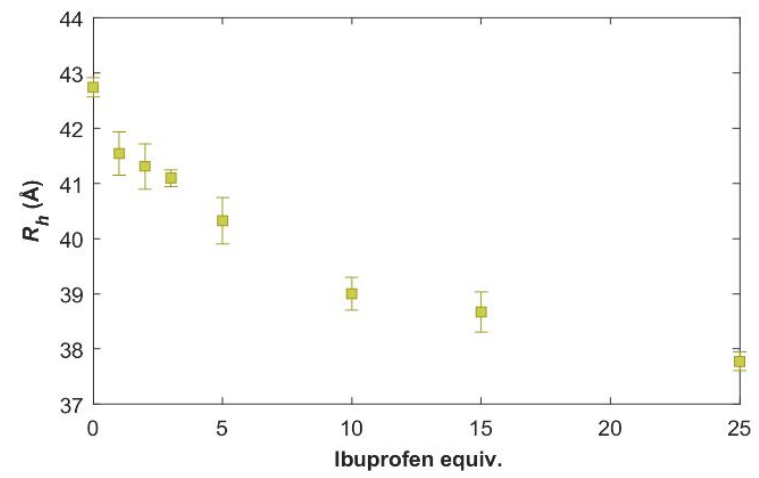

Figure 7. DLS competition experiment where the albumindetemir complex is titrated with ibuprofen. With the addition of one ibuprofen equivalent (per albumin-hexamer complex), a significant decrease in $R_{h}$ is observed indicating that the complex dissociates to a mixture of albumin and detemir.

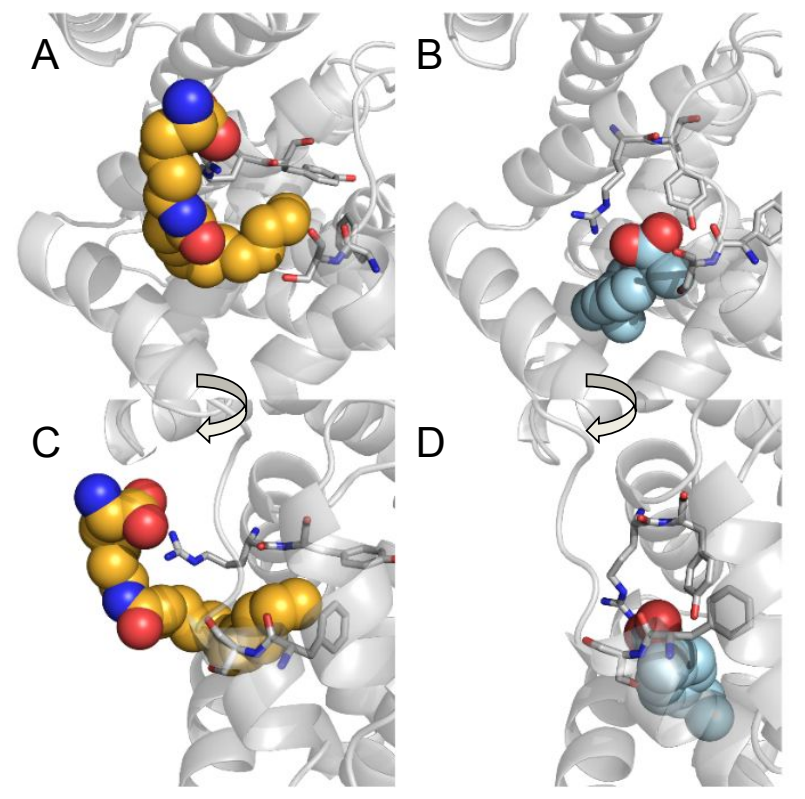

Figure 8. The binding poses of Aly D29 (orange) from the FA4b simulation (A) and (C) and ibuprofen (PDB entry: $2 \mathrm{BXG}_{5}$, light blue) (B) and (D) are compared. (C) and (D) are rotated $60^{\circ}$ relative to (A) and (B). The structures have been aligned on the five alpha helices surrounding ibuprofen. The residues responsible for ibuprofen binding are shown as sticks.

detemir binding site. Intuitively, this seems to be contradicted by the SAXS fits of the FAr complexes that indicate that FAl binding is not observed in the experiments. This discrepancy can be explained by the $1: 6$ molar albumin:detemir ratio used in the SAXS experiments. At this ratio, the detemir hexamer solely saturates the primary binding site, and we would therefore not expect that a complex with binding at a secondary site fits the SAXS data. Our study can thus not exclude that FA1 could be a secondary binding site, but the main focus of the study is to investigate detemir's primary binding site. Trajectory analysis, binding free energy calculations and interface analysis suggest that $\mathrm{FA}_{4}$ is the primary binding site.

To experimentally test whether detemir does indeed bind at FA4, DLS competition experiments were set up, where the albumin-hexamer complex was titrated with ibuprofen. While ibuprofen is proposed to have multiple binding sites on albumin, there is a consensus that FA4 is the primary ibuprofen binding site with a $\sim 10-100$ times higher affinity than for the secondary ibuprofen binding site FA6.94 The primary association constants of ibuprofen and detemir have been determined under the same experimental conditions to be $2.7 \cdot 10^{6} \mathrm{M}^{-1}$ and $2.4 \cdot 10^{5} \mathrm{M}$ ${ }^{1}$, respectively. ${ }^{18}$ The addition of one ibuprofen equivalent can thus be expected to compete with detemir binding. With respect to possible allosteric effects, crystal structures of albumin with and without ibuprofen are compared. The backbone RMSD of the structures (PDB entries: $1 \mathrm{AO}^{84}$ and ${ }^{2} \mathrm{BXG}^{5}$ ) is $0.7 \AA$, indicating that ibuprofen binding to $\mathrm{FA}_{4}$ does not lead to conformational changes in albumin. This is in agreement with previous studies showing ibuprofen binding to $\mathrm{FA}_{4}$ may not be allosterically linked to the FAr binding site. ${ }^{95,96}$ In the competition experiment, the addition of one ibuprofen equivalent leads to a decrease in $R_{h}$ indicating complex dissociation. For the above-mentioned reasons, the decrease in $R_{h}$ can be considered an competition effect of ibuprofen binding to FA4, which confirms $\mathrm{FA}_{4}$ as the correct binding site. This result is in agreement with the findings of Kjeldsen et al. ${ }^{19}$ that detemir binds to albumin's domain III in which FA4 is embedded.

Another competition study of the albumin-detemir complex formation was carried out by Kurtzhals et al. ${ }^{18}$ The authors found that detemir could be displaced from albumin when more than one ibuprofen equivalent was added and that another $\mathrm{FA}_{4}$ ligand, diazepam, could not displace detemir. Based on this, the authors suggested that FA4 may not be the correct binding site. Their observation that diazepam cannot displace detemir can be explained by a crystal structure of albumin with diazepam bound (PDB entry: 2BXF5) that was published after the study of Kurtzhals et al. The crystal structure reveals that diazepam binds more deeply into the $\mathrm{FA}_{4}$ binding site than 
ibuprofen does, and therefore does not compete with detemir Aly binding (Supplementary Figure S18).

Detemir's binding site on albumin has previously been investigated using in-silico approaches by Fatima et al. ${ }^{20}$ who based on docking proposed that detemir's chain B binds near FA1. The result is not directly comparable with ours, as the binding of a hexamer can be expected to differ significantly from the binding of only chain B of a detemir monomer. In particular, we observe that not only hydrophobic Aly (chain B) interactions are present in the albumin-detemir interface but also salt bridges and hydrogen bonds formed by residues in both chain A and $\mathrm{B}$ of detemir (Figure 6).

The binding free energy of the albumin-detemir complex has been determined experimentally to $-7.1 \mathrm{kcal} / \mathrm{mol}$ by Kurtzhals et al..$^{87}$ and $-3.8 \mathrm{kcal} / \mathrm{mol}$ by Fatima et al. ${ }^{20}$. The deviation between the binding energies could reflect the different experimental conditions. In comparison, we calculated a lower binding energy of $-28 \pm 6 \mathrm{kcal} / \mathrm{mol}$ for the most favorable $\mathrm{FA}_{4}$ complexes. Such an overestimation of binding energies is commonly observed for the MM-PBSA approach. ${ }^{68,72,73,97}$ The strength of the method is not to estimate absolute binding energies but to rank proteinprotein and protein-peptide complexes based on their relative energies, ${ }^{48,97,98}$ which puts confidence into the ranking of the albumin-detemir complexes.

In addition to ranking, the MM-PBSA results can give an indication of which energy terms contribute to the stability of the albumin-detemir complex. For the FA4 binding site, especially the electrostatic and $\mathrm{vdW}$ gas-phase energies are stabilizing the complexes. This result fits well with the findings of Kurtzhals et al. ${ }^{87}$ who found that both ionic and non-polar interactions contribute to the complex stability. For the ionic interactions, the authors observed that adding an extra residue to detemir's $\mathrm{B}$ chain $\left(\mathrm{Thr}^{\mathrm{B}} \mathrm{B}^{\mathrm{O}}\right)$ resulted in a weaker albumin binding suggesting that positioning the $\mathrm{C}$-terminal on position 29 is favorable. The authors propose that this is due to an ionic interaction between the C-terminal carboxylate and a basic albumin residue. Indeed, in both $\mathrm{FA}_{4 a}$ and $\mathrm{FA}_{4} \mathrm{~b}$, strong interactions are observed between the Aly ${ }^{\mathrm{D} 29} \mathrm{C}$-terminal carboxylate and $\mathrm{Arg}^{410}$ (Figure 6A) and the $\mathrm{Aly}^{\mathrm{H} 29} \mathrm{C}$ terminal carboxylate and Lys ${ }^{372}$ (Figure 6B). For the nonpolar interactions, Kurtzhals et al. ${ }^{87}$ found that increasing the length of the Aly fatty acid chain up to 14 carbons led to a stronger binding and concluded that the Aly acyl chain takes part in the interaction with albumin. The many Alyalbumin interactions in the FA4 heatmaps (Figure $5 \mathrm{~A}$ and and Supplementary Figure $\mathrm{S}_{12} \mathrm{~A}$ ) clearly show that this is the case for the $\mathrm{FA}_{4}$ binding site. The agreement between our study and the predictions by Kurtzhals et al. ${ }^{87}$ puts further confidence in $\mathrm{FA}_{4}$ as the correct binding site.

While Kurtzhals et al. ${ }^{87}$ find that both electrostatic and hydrophobic interactions are important, Fatima et al. ${ }^{20}$ find that the complex formation is dominated by hydrophobic interaction. These findings are not contradictory, as hydrophobic interactions are generally found to be the driving interactions in protein-protein complexes, whereas the long-range electrostatic interactions are steering in the complex formation and contribute to interaction specificity. ${ }^{90,99-101}$ In agreement with the results of Fatima et al. ${ }^{20}$, we have found that addition of $\mathrm{NaCl}$ promotes complex formation (Supplementary Figure S19), which indicates that hydrophobic interactions stabilize the albumin-detemir complex.

\section{CONCLUSION}

In this work, we have studied a complex between a detemir hexamer and albumin using MD simulations in combination with MM-PBSA free energy calculations and DLS competition studies. The simulations were set up based on SAXS results ${ }^{22}$ suggesting that detemir can bind to albumin close to the albumin fatty acid binding sites, $\mathrm{FA}$, FA6, FA7, or the overlapping binding sites $\mathrm{FA}_{3}-\mathrm{FA}_{4}$ (named $\mathrm{FA}_{4}$ ). The simulations were performed in duplicates for $200 \mathrm{~ns}$.

The $\mathrm{FA}_{4}$ simulations had the best fits to the experimental SAXS data with an average $\chi^{2}$ of $2.4 \pm 0.4$, and the lowest binding free energies with an average of $-28 \pm 6$ $\mathrm{kcal} / \mathrm{mol}$.

Several electrostatic interactions were identified between detemir and albumin: $\mathrm{Glu}^{\mathrm{C}} 4-\mathrm{Lys}^{414}$ (notation: detemir residue-albumin residue), $\mathrm{Glu}^{\mathrm{C}_{4}-\mathrm{Arg}^{410}}{ }^{4}$, $\mathrm{Aly}^{\mathrm{D} 29}$

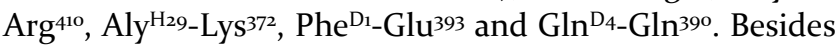
the specific interactions, we also monitored hydrophobic interactions between the fatty acid residue (Aly) and albumin. The hydrophobic interactions stemming from the Aly residues were found to be an important contribution to the free energy of binding as quantified by MM-PBSA analysis. The binding of detemir to $\mathrm{FA}_{4}$ was confirmed by a DLS competition experiment in which albumin-detemir complexes were titrated with the $\mathrm{FA}_{4}$ ligand, ibuprofen. Upon addition of one ibuprofen equivalent, a decrease in $R_{h}$ was observed indicating that detemir was displaced by direct competition.

Thus based on structural and energetic analyses of MD simulations, competition experiments and comparison with the detailed studies by Kurtzhals et al. ${ }^{18,87}$, we propose that $\mathrm{FA}_{4}$ is the most probable binding site for detemir. The results give a molecular insight into the binding of a lipidated peptide to albumin that could be exploited in the design of future drugs.

\section{ASSOCIATED CONTENT}

Supporting information:

Additional RMSD plots based on albumin and the hexamer structures; time evolutions of $R_{g}$, center-of-mass, electrostatic and vdW binding energies; Interaction heat maps; Clustered structures of the simulated complexes; Figure of the FA4a binding interface; Comparison of the $\mathrm{FA}_{4} \mathrm{~b}$ detemir binding pose with the diazepam binding pose; SAXS data and analysis for titration with $\mathrm{NaCl}$; $\mathrm{CHARMM}_{3} 6$ topology entry for the Aly residue. 
This material is available free of charge via the Internet at http://pubs.acs.org.

\section{AUTHOR INFORMATION}

\section{Corresponding Author}

* linear@kemi.dtu.dk

* ghp@kemi.dtu.dk

\section{Author Contributions}

All authors have given approval to the final version of the manuscript.

\section{Funding Sources}

We would like to acknowledge DTU Chemistry at the Technical University of Denmark for funding of the PhD scholarship.

\section{ACKNOWLEDGMENT}

We would like to acknowledge MAX IV Laboratories for providing beam time for the SAXS experiments. Albumedix Ltd is acknowledged for providing albumin for the experiments. We thank the Danish Agency for Science, Technology, and Innovation for funding the instrument center DanScatt.

\section{ABBREVIATIONS}

Aly, acylated lysine; DLS, dynamic light scattering; MD, molecular dynamics; MM-PBSA, molecular mechanics Poisson-Boltzmann surface area; RMSD, root-mean-square deviation; SAXS, small-angle X-ray scattering.

\section{REFERENCES}

(1) Fanali, G.; di Masi, A.; Trezza, V.; Marino, M.; Fasano, M.; Ascenzi, P. Human Serum Albumin: From Bench to Bedside. Mol. Aspects Med. 2012, 33, 209-290.

(2) Zunszain, P. A.; Ghuman, J.; McDonagh, A. F.; Curry, S. Crystallographic Analysis of Human Serum Albumin Complexed with 4Z,15E-Bilirubin-IX $\alpha$. J. Mol. Biol. 2oo8, 381, 394-406.

(3) Sudlow, G.; Birkett, D. J.; Wade, D. N. The Characterization of Two Specific Drug Binding Sites on Human Serum Albumin. Mol. Pharmacol. 1975, 11, 824-832.

(4) Zsila, F. Subdomain IB Is the Third Major Drug Binding Region of Human Serum Albumin: Toward the Three-Sites Model. Mol. Pharm. 2013, 10, 1668-1682.

(5) Ghuman, J.; Zunszain, P. A.; Petitpas, I.; Bhattacharya, A. A.; Otagiri, M.; Curry, S. Structural Basis of the Drug-Binding Specificity of Human Serum Albumin. J. Mol. Biol. 2005, 353, 38-52.

(6) Sleep, D.; Cameron, J.; Evans, L. R. Albumin as a Versatile Platform for Drug Half-Life Extension. Biochim. Biophys. Acta - Gen. Subj. 2013, 1830, 5526-5534.

(7) Henninot, A.; Collins, J. C.; Nuss, J. M. The Current State of Peptide Drug Discovery: Back to the Future? J. Med. Chem. 2018, 61, 1382-1414.

(8) Lau, J. L.; Dunn, M. K. Therapeutic Peptides: Historical Perspectives, Current Development Trends, and Future Directions. Bioorganic Med. Chem. 2018, 26, 2700-2707.

(9) Menacho-Melgar, R.; Decker, J. S.; Hennigan, J. N.; Lynch, M. D. A Review of Lipidation in the Development of Advanced Protein and Peptide Therapeutics. J. Control. Release 2019, 295, 1-12.

(10) Adams, G. G.; Meal, A.; Morgan, P. S.; Alzahrani, Q. E.; Zobel, H.; Lithgo, R.; Kok, M. S.; Besong, D. T. M.; Jiwani, S. I.; Ballance, S.; et al. Characterisation of Insulin Analogues
Therapeutically Available to Patients. PLoS One 2018, 13, eo195010.

(11) Adams, G. G.; Alzahrani, Q.; Jiwani, S. I.; Meal, A.; Morgan, P. S.; Coffey, F.; Kok, S.; Rowe, A. J.; Harding, S. E.; Chayen, N.; et al. Glargine and Degludec: Solution Behaviour of Higher Dose Synthetic Insulins. Sci. Rep. 2017, 7, 1-11.

Jonassen, I.; Havelund, S.; Hoeg-Jensen, T.; Steensgaard, D. B.; Wahlund, P.-O.; Ribel, U. Design of the Novel Protraction Mechanism of Insulin Degludec, an Ultra-Long-Acting Basal Insulin. Pharm. Res. 2012, 29, 2104-2114.

(13) Whittingham, J., L.; Jonassen, I.; Havelund, S.; Roberts, Sh., M.; Dodson, E., J.; Verma, C., S.; Wilkinson, A., J.; Dodson, G., G. Crystallographic and Solution Studies of N-Lithocholyl Insulin: A New Generation of Prolonged-Acting Human Insulins. Biochemistry 2004, 43, 5987-5995.

(14) Jensen, M. H.; Wahlund, P.-O.; Toft, K. N.; Jacobsen, J. K.; Steensgaard, D. B.; van de Weert, M.; Havelund, S.; Vestergaard, B. Small Angle X-ray Scattering-Based Elucidation of the Self- Association Mechanism of Human

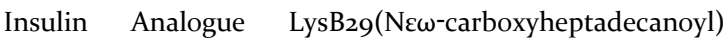
Des(B30). Biochemistry 2013, 52, 282-294.

(15) Olsen, H. B.; Kaarsholm, N. C. Structural Effects of Protein Lipidation as Revealed by Lys B29 -Myristoyl, Des(B3o) Insulin. Biochemistry 2000, 39, 11893-11900.

(16) Steensgaard, D. B.; Schluckebier, G.; Strauss, H. M.; Norrman, M.; Thomsen, J. K.; Friderichsen, A. V.; Havelund, S.; Jonassen, I. Ligand-Controlled Assembly of Hexamers, Dihexamers, and Linear Multihexamer Structures by the Engineered Acylated Insulin Degludec. Biochemistry 2013, 52, 295-309.

(17) Frederiksen, T. M.; Sønderby, P.; Ryberg, L. A.; Harris, P.; Bukrinski, J. T.; Scharff-poulsen, A. M.; Elf-lind, M. N. Oligomerization of a Glucagon-like Peptide 1 Analog: Bridging Experiment and Simulations. Biophys. J. 2015, 109, 1202-1213.

(18) Kurtzhals, P.; Havelund, S.; Jonassen, I.; Markussen, J. Effect of Fatty Acids and Selected Drugs on the Albumin Binding of a Long-Acting, Acylated Insulin Analogue. J. Pharm. Sci. 1997, 86, 1365-1368.

(19) Kjeldsen, T.; Pettersson, A. F.; Drube, L.; Kurtzhals, P.; Jonassen, I.; Havelund, S.; Hansen, P. H.; Markussen, J. Secretory Expression of Human Albumin Domains in Saccharomyces Cerevisiae and Their Binding of Myristic Acid and an Acylated Insulin Analogue. Protein Expr. Purif. 1998, 13, 163-169.

(20) Fatima, S.; Sen, P.; Sneha, P.; Priyadoss, C. G. Hydrophobic Interaction Between Domain I of Albumin and B Chain of Detemir May Support Myristate-Dependent DetemirAlbumin Binding. Appl. Biochem. Biotechnol. 2017, 182, 8296.

(21) Havelund, S.; Plum, A.; Ribel, U.; Jonassen, I.; Vølund, A.; Markussen, J.; Kurtzhals, P. The Mechanism of Protraction of Insulin Detemir, a Long-Acting, Acylated Analog of Human Insulin. Pharm. Res. 2004, 21, 1498-1504.

(22) Ryberg, L. A.; Sønderby, P.; Barrientos, F.; Bukrinski, J. T.; Peters, G. H. J.; Harris, P. Solution Structures of Long-Acting Insulin Analogues and Their Complexes with Albumin. Acta Crystallogr. Sect. D 2019, 75, 272-282.

(23) Banerjee, P.; Mondal, S.; Bagchi, B. Insulin Dimer Dissociation in Aqueous Solution: A Computational Study of Free Energy Landscape and Evolving Microscopic Structure along the Reaction Pathway. J. Chem. Phys. 2018, 149, 114902.

(24) El Hage, K.; Mondal, P.; Meuwly, M. Free Energy Simulations for Protein Ligand Binding and Stability. Mol. Simul. 2018, 44, 1044-1061.

(25) Kim, Y. H.; Kastner, K.; Abdul-Wahid, B.; Izaguirre, J. A. Evaluation of Conformational Changes in DiabetesAssociated Mutation in Insulin a Chain: A Molecular Dynamics Study. Proteins Struct. Funct. Bioinforma. 2015, 83, 662-669.

(26) Ong, S. C.; Belgi, A.; Van Lierop, B.; Delaine, C.; 
Andrikopoulos, S.; MacRaild, C. A.; Norton, R. S.; Haworth, N. L.; Robinson, A. J.; Forbes, B. E. Probing the Correlation between Insulin Activity and Structural Stability through Introduction of the Rigid A6 -A11 Bond. J. Biol. Chem. 2018, 293, 11928-11943.

(27) Rege, N. K.; Wickramasinghe, N. P.; Tustan, A. N.; Phillips, N. F. B.; Yee, V. C.; Ismail-Beigi, F.; Weiss, M. A. StructureBased Stabilization of Insulin as a Therapeutic Protein Assembly via Enhanced Aromatic-Aromatic Interactions. J. Biol. Chem. 2018, 293, 10895-10910.

(28) Březina, K.; Duboué-Dijon, E.; Palivec, V.; Jiráček, J.; Křížek, T.; Viola, C. M.; Ganderton, T. R.; Brzozowski, A. M. Jungwirth, P. Can Arginine Inhibit Insulin Aggregation? A Combined Protein Crystallography, Capillary Electrophoresis, and Molecular Simulation Study. J. Phys. Chem. B 2018, 122, 10069-10076.

(29) Muhammad, E. F.; Adnan, R.; Latif, M. A. M.; Rahman, M. B. A. Theoretical Investigation on Insulin Dimer- $\beta$ Cyclodextrin Interactions Using Docking and Molecular Dynamics Simulation. J. Incl. Phenom. Macrocycl. Chem. 2015, 84, 1-10.

(30) Mukherjee, S.; Mondal, S.; Deshmukh, A. A.; Gopal, B.; Bagchi, B. What Gives an Insulin Hexamer Its Unique Shape and Stability? Role of Ten Confined Water Molecules. J. Phys. Chem. B 2018, 122, 1631-1637.

(31) Raghunathan, S.; El Hage, K.; Desmond, J. L.; Zhang, L.; Meuwly, M. The Role of Water in the Stability of Wild-Type and Mutant Insulin Dimers. J. Phys. Chem. B 2018, 122, 70387048 .

(32) Yeggoni, D. P.; Gokara, M.; Mark Manidhar, D.; Rachamallu, A.; Nakka, S.; Reddy, C. S.; Subramanyam, R. Binding and Molecular Dynamics Studies of 7-Hydroxycoumarin Derivatives with Human Serum Albumin and Its Pharmacological Importance. Mol. Pharm. 2014, 11, 1117-1131.

(33) Evoli, S.; Mobley, D. L.; Guzzi, R.; Rizzuti, B. Multiple Binding Modes of Ibuprofen in Human Serum Albumin Identified by Absolute Binding Free Energy Calculations. Phys. Chem. Chem. Phys. 2016, 18, 32358-32368.

(34) Xiong, X.; Gan, R.; Suo, Z.; Tang, P.; Zhang, S.; Zhu, Y.; Sun, Q.; Li, H. Interactions between the Antiviral Drug Telaprevir and Human Serum Albumin: A Combined Study with Spectroscopic Methods and Molecular Modeling. New J. Chem. 2018, 42, 9791-980o.

(35) Salvalaglio, M.; Muscionico, I.; Cavallotti, C. Determination of Energies and Sites of Binding of PFOA and PFOS to Human Serum Albumin. J. Phys. Chem. B 2010, 114, 1486o14874 .

(36) Pongprayoon, P.; Mori, T. The Critical Role of Dimer Formation in Monosaccharides Binding to Human Serum Albumin. Phys. Chem. Chem. Phys. 2018, 20, 3249-3257.

(37) Niu, X.; Gao, X.; Wang, H.; Wang, X.; Wang, S. Insight into the Dynamic Interaction between Different Flavonoids and Bovine Serum Albumin Using Molecular Dynamics Simulations and Free Energy Calculations. J. Mol. Model. 2013, 19, 1039-1047.

(38) Bolel, P.; Datta, S.; Mahapatra, N.; Halder, M. Exploration of PH-Dependent Behavior of the Anion Receptor Pocket of Subdomain IIA of HSA: Determination of Effective Pocket Charge Using the Debye-Hückel Limiting Law. J. Phys. Chem. B 2014, 118, 26-36.

(39) Becconi, O.; Ahlstrand, E.; Salis, A.; Friedman, R. Protein-Ion Interactions: Simulations of Bovine Serum Albumin in Physiological Solutions of $\mathrm{NaCl}, \mathrm{KCl}$ and LiCl. Isr. J. Chem. 2017, 57, 403-412.

(40) Fujiwara, S.; Amisaki, T. Fatty Acid Binding to Serum Albumin: Molecular Simulation Approaches. Biochim. Biophys. Acta 2013, 1830, 5427-5434.

(41) Rizzuti, B.; Bartucci, R.; Sportelli, L.; Guzzi, R. Fatty Acid Binding into the Highest Affinity Site of Human Serum Albumin Observed in Molecular Dynamics Simulation. Arch. Biochem. Biophys. 2015, 579, 18-25.
(42) Luo, Q.; Wang, Y.; Yang, H.; Liu, C.; Ding, Y.; Xu, H.; Wang, Q.; Liu, Y.; Xie, Y. Modeling the Interaction of Interferon $\alpha-$ $1 \mathrm{~b}$ to Bovine Serum Albumin as a Drug Delivery System. J. Phys. Chem. B 2014, 118, 8566-8574.

(43) Wang, B.; Sun, Y.; Davis, T. P.; Ke, P. C.; Wu, Y.; Ding, F. Understanding Effects of PAMAM Dendrimer Size and Surface Chemistry on Serum Protein Binding with Discrete Molecular Dynamics Simulations. ACS Sustain. Chem. Eng. 2018, 6, 11704-11715.

(44) Tiwari, G.; Verma, C. S. Toward Understanding the Molecular Recognition of Albumin by $\mathrm{P}_{53}$-Activating Stapled Peptide ATSP-7041. J. Phys. Chem. B 2017, 121, 657670.

(45) Paris, G.; Ramseyer, C.; Enescu, M. A Principal Component Analysis of the Dynamics of Subdomains and Binding Sites in Human Serum Albumin. Biopolymers 2014, 101, 561-572.

(46) Wereszczynski, J.; McCammon, J. A. Statistical Mechanics and Molecular Dynamics in Evaluating Thermodynamic Properties of Biomolecular Recognition. Q. Rev. Biophys. 2012, 45, 1-25.

(47) Fujiwara, S.; Amisaki, T. Identification of High Affinity Fatty Acid Binding Sites on Human Serum Albumin by MM-PBSA Method. Biophys. J. 2008, 94, 95-103.

(48) Simões, I. C. M.; Coimbra, J. T. S.; Neves, R. P. P.; Costa, I. P. D.; Ramos, M. J.; Fernandes, P. A.; Neves, R. P. P. Properties That Rank Protein: Protein Docking Poses. Phys. Chem. Chem. Phys. 2018, 20, 20927-20942.

(49) Ruan, W.; Kang, Z.; Li, Y.; Sun, T.; Wang, L.; Liang, L.; Lai, M.; Wu, T. Interaction between $\mathrm{IGFBP}_{7}$ and Insulin: A Theoretical and Experimental Study. Sci. Rep. 2016, 6, 19586.

(50) Vashisth, H.; Abrams, C. F. All-Atom Structural Models of Insulin Binding to the Insulin Receptor in the Presence of a Tandem Hormone-Binding Element. Proteins Struct. Funct. Bioinforma. 2013, 81, 1017-1030.

(51) Whittingham, J. L.; Havelund, S.; Jonassen, I. Crystal Structure of a Prolonged-Acting Insulin with AlbuminBinding Properties. Biochemistry 1997, 36, 2826-2831.

(52) Curry, S.; Mandelkow, H.; Brick, P.; Franks, N. Crystal Structure of Human Serum Albumin Complexed with Fatty Acid Reveals an Asymmetric Distribution of Binding Sites. Nat. Struct. Biol. 1998, 5, 827-835.

(53) Bhattacharya, A. A.; Grüne, T.; Curry, S. Crystallographic Analysis Reveals Common Modes of Binding of Medium and Long-Chain Fatty Acids to Human Serum Albumin. J. Mol. Biol. 2000, 303, 721-732.

（54） Best, R. B.; Zhu, X.; Shim, J.; Lopes, P. E. M.; Mittal, J.; Feig, M.; MacKerell, A. D. Optimization of the Additive CHARMM All-Atom Protein Force Field Targeting Improved Sampling of the Backbone $\phi, \psi$ and Side-Chain X1and X2Dihedral Angles. J. Chem. Theory Comput. 2012, 8, 3257-3273.

(55) MacKerell, A. D.; Bashford, D.; Bellott, M.; Dunbrack, R. L.; Evanseck, J. D.; Field, M. J.; Fischer, S.; Gao, J.; Guo, H.; Ha, S.; et al. All-Atom Empirical Potential for Molecular Modeling and Dynamics Studies of Proteins ${ }^{\dagger}$. J. Phys. Chem. B 1998, 102, 3586-3616.

(56) MacKerell, A. D.; Feig, M.; Brooks, C. L. Improved Treatment of the Protein Backbone in Empirical Force Fields. J. Am. Chem. Soc. 2004, 126, 698-699.

(57) Stote, R. H.; Karplus, M. Zinc Binding in Proteins and Solution: A Simple but Accurate Nonbonded Representation. 1995, 31, 12-31.

(58) Beglov, D.; Roux, B. Finite Representation of an Infinite Bulk System: Solvent Boundary Potential for Computer Simulations. J. Chem. Phys. 1994, 100, 9050-9063.

(59) Davis, I. W.; Leaver-Fay, A.; Chen, V. B.; Block, J. N.; Kapral, G. J.; Wang, X.; Murray, L. W.; Arendall, W. B.; Snoeyink, J.; Richardson, J. S.; et al. MolProbity: All-Atom Contacts and Structure Validation for Proteins and Nucleic Acids. Nucleic Acids Res. 2007, 35, W375-W383.

(6o) Chen, V. B.; Arendall, W. B.; Headd, J. J.; Keedy, D. A.; Immormino, R. M.; Kapral, G. J.; Murray, L. W.; Richardson, 
J. S.; Richardson, D. C. MolProbity: All-Atom Structure Validation for Macromolecular Crystallography. Acta Crystallogr. Sect. D Biol. Crystallogr. 2010, 66, 12-21.

(61) Jorgensen, W. L.; Chandrasekhar, J.; Madura, J. D.; Impey, R. W.; Klein, M. L.; Jorgensen, W. L.; Chandrasekhar, J.; Madura, J. D.; Impey, R. W.; Klein, M. L. Comparison of Simple Potential Functions for Simulating Liquid Water. J. Chem. Phys. 1983, 79, 926-935.

(62) Phillips, J. C.; Braun, R.; Wang, W.; Gumbart, J.; Tajkhorshid, E.; Villa, E.; Chipot, C.; Skeel, R. D.; Kalé, L.; Schulten, K. Scalable Molecular Dynamics with NAMD.J. Comput. Chem. 2005, 26, 1781-1802.

(63) Feller, S. E.; Zhang, Y.; Pastor, R. W.; Brooks, B. R. Constant Pressure Molecular Dynamics Simulation: The Langevin Piston Method. J. Chem. Phys. 1995, 103, 4613-4621.

(64) Darden, T.; York, D.; Pedersen, L. Particle Mesh Ewald: An N $\cdot \log (\mathrm{N})$ Method for Ewald Sums in Large Systems. J. Chem. Phys. 1993, 98, 10089-10092.

(65) Essmann, U.; Perera, L.; Berkowitz, M. L.; Darden, T.; Lee, H.; Pedersen, L. G. A Smooth Particle Mesh Ewald Method. J. Chem 1995, 103, 8577-8593.

(66) Ryckaert, J. P.; Ciccotti, G.; Berendsen, H. J. C. Numerical Integration of the Cartesian Equations of Motion of a System with Constraints: Molecular Dynamics of n-Alkanes. J. Comput. Phys. 1977.

(67) Svergun, D.; Barberato, C.; Koch, M. H. J. CRYSOL - a Program to Evaluate X-Ray Solution Scattering of Biological Macromolecules from Atomic Coordinates. J. Appl. Crystallogr. 1995, 28, 768-773.

(68) Gohlke, H.; Case, D. A. Converging Free Energy Estimates: MM-PB(GB)SA Studies on the Protein-Protein Complex RasRaf. J. Comput. Chem. 2004, 25, 238-250.

(69) Simões, I. C. M.; Costa, I. P. D.; Coimbra, J. T. S.; Ramos, M. J.; Fernandes, P. A. New Parameters for Higher Accuracy in the Computation of Binding Free Energy Differences upon Alanine Scanning Mutagenesis on Protein-Protein Interfaces. J. Chem. Inf. Model. 2017, 57, 60-72.

(70) Baker, N. A.; Sept, D.; Joseph, S.; Holst, M. J.; McCammon, J. A. Electrostatics of Nanosystems: Application to Microtubules and the Ribosome. Proc. Natl. Acad. Sci. 2oo1, 98, 10037-10041.

(71) Dolinsky, T. J.; Nielsen, J. E.; Mccammon, J. A.; Baker, N. A. PDB2PQR : An Automated Pipeline for the Setup of Poisson - Boltzmann Electrostatics Calculations. Nucleic Acids Res. 2004, 32, W665-W667.

(72) Genheden, S.; Ryde, U. The MM/PBSA and MM/GBSA Methods to Estimate Ligand-Binding Affinities. Expert Opin. Drug Discov. 2015, 10, 449-461.

(73) Hou, T.; Wang, J.; Li, Y.; Wang, W. Assessing the Performance of the MM/PBSA and MM/GBSA Methods: I. The Accuracy of Binding Free Energy Calculations Based on Molecular Dynamics Simulations. J. Comput. Chem. 2011, 32, 866-877.

(74) Chen, F.; Liu, H.; Sun, H.; Pan, P.; Li, Y.; Li, D.; Hou, T. Assessing the Performance of the MM/PBSA and MM/GBSA Methods. 6. Capability to Predict Protein-Protein Binding Free Energies and Re-Rank Binding Poses Generated by Protein-Protein Docking. Phys. Chem. Chem. Phys. 2016, 18, 22129-22139.

(75) Flyvbjerg, H.; Petersen, H. G. Error Estimates on Averages of Correlated Data. J. Chem. Phys. 1989, 91, 461-466.

(76) Wang, C.; Greene, D.; Xiao, L.; Qi, R.; Luo, R. Recent Developments and Applications of the MMPBSA Method. Front. Mol. Biosci. 2018, 4, 1-18.

(77) Rodrigues, J. P. G. L. M.; Trellet, M.; Schmitz, C.; Kastritis, P.; Karaca, E.; Melquiond, A. S. J.; Bonvin, A. M. J. J. Clustering Biomolecular Complexes by Residue Contacts Similarity. Proteins Struct. Funct. Bioinforma. 2012, 8o, 1810-1817.

(78) Labrador, A.; Cerenius, Y.; Svensson, C.; Theodor, K.; Plivelic, T. The Yellow Mini-Hutch for SAXS Experiments at MAX IV Laboratory. J. Phys. Conf. Ser. 2013, 425, 1-4.
(79) Petoukhov, M. V.; Svergun, D. I. Global Rigid Body Modeling of Macromolecular Complexes against Small-Angle Scattering Data. Biophys. J. 2005, 89, 1237-1250.

(8o) Petoukhov, M. V.; Svergun, D. I. Joint Use of Small-Angle XRay and Neutron Scattering to Study Biological Macromolecules in Solution. Eur. Biophys. J. 20o6, 35, 567576.

(81) Blanchet, C. E.; Spilotros, A.; Schwemmer, F.; Graewert, M. A.; Kikhney, A.; Jeffries, C. M.; Franke, D.; Mark, D.; Zengerle, R.; Cipriani, F.; et al. Versatile Sample Environments and Automation for Biological Solution X-Ray Scattering Experiments at the P12 Beamline (PETRA III, DESY). J. Appl. Crystallogr. 2015, 48, 431-443.

(82) Franke, D.; Petoukhov, M. V.; Konarev, P. V.; Panjkovich, A.; Tuukkanen, A.; Mertens, H. D. T.; Kikhney, A. G.; Hajizadeh, N. R.; Franklin, J. M.; Jeffries, C. M.; et al. ATSAS 2.8: A Comprehensive Data Analysis Suite for Small-Angle Scattering from Macromolecular Solutions. J. Appl. Crystallogr. 2017, 50, 1151-1158.

(83) Konarev, P. V.; Volkov, V. V.; Sokolova, A. V.; Koch, M. H. J.; Svergun, D. I. PRIMUS : A Windows PC-Based System for Small-Angle Scattering Data Analysis. J. Appl. Crystallogr. 2003, 36, 1277-1282.

(84) Sugio, S.; Kashima, A.; Mochizuki, S.; Noda, M.; Kobayashi, K. Crystal Structure of Human Serum Albumin at 2.5 A Resolution. Protein Eng. 1999, 12, 439-446.

(85) Ciszak, E.; Smith, G. D. Crystallographic Evidence for Dual Coordination around Zinc in the $\mathrm{T}_{3} \mathrm{R}_{3}$ Human Insulin Hexamer ${ }^{\wedge}$ ' i. 1994, 1512-1517.

(86) Valentini, E.; Kikhney, A. G.; Previtali, G.; Jeffries, C. M.; Svergun, D. I. SASBDB, a Repository for Biological SmallAngle Scattering Data. Nucleic Acids Res. 2015, 43, D357D363.

(87) Kurtzhals, P.; Havelund, S.; Jonassen, I.; Kiehr, B.; Larsen, U. D.; Ribel, U.; Markussen, J. Albumin Binding of Insulins Acylated with Fatty Acids: Characterization of the LigandProtein Interaction and Correlation between Binding Affinity and Timing of the Insulin Effect in Vivo. Biochem. J. 1995, 312, 725-731.

(88) Sleep, D. Expert Opinion on Drug Delivery Albumin and Its Application in Drug Delivery. Expert Opin. Drug Deliv. 2014, 12, 793-812.

(89) Dong, F.; Zhou, H.-X. Electrostatic Contribution to the Binding Stability of Protein-Protein Complexes. Proteins Struct. Funct. Bioinforma. 2006, 65, 87-102.

(90) Zhou, H. X.; Pang, X. Electrostatic Interactions in Protein Structure, Folding, Binding, and Condensation. Chem. Rev. 2018, 118, 1691-1741.

(91) Carter, D. C.; Ho, J. X. Structure of Serum Albumin. Adv. Protein Chem. 1994, 45, 153-203.

(92) Fanali, G.; Trezza, V.; Marino, M.; Fasano, M.; Ascenzi, P. Human Serum Albumin: From Bench to Bedside. Mol. Aspects Med. 2012, 33, 209-290.

(93) Peters, T. Ligand Binding by Albumin. In All About Albumin; Peters, T., Ed.; Academic Press: San Diego, 1995; pp 76-132.

(94) Ràfols, C.; Zarza, S.; Bosch, E. Molecular Interactions between Some Non-Steroidal Anti-Inflammatory Drugs (NSAID's) and Bovine (BSA) or Human (HSA) Serum Albumin Estimated by Means of Isothermal Titration Calorimetry (ITC) and Frontal Analysis Capillary Electrophores (FA/CE). Talanta 2014, 130, 241-250.

(95) Ascenzi, P.; Masi, A.; Coletta, M.; Ciaccio, C.; Fanali, G.; Nicoletti, F. P.; Smulevich, G.; Fasano, M. Ibuprofen Impairs Allosterically Peroxynitrite Isomerization by Ferric Human Serum Heme-Albumin. 2009, 284, 31006-31017.

(96) Ascenzi, P.; Sanctis, G. De; Coletta, M.; Fasano, M. Ibuprofen Modulates Allosterically NO Dissociation from Ferrous Nitrosylated Human Serum Heme-Albumin by Binding to Three Sites. Biochem. Biophys. Res. Commun. 2oo9, 387, 8386.

(97) Spiliotopoulos, D.; Kastritis, P. L.; Melquiond, A. S. J.; 
Bonvin, A. M. J. J.; Musco, G.; Rocchia, W.; Spitaleri, A. DMM-PBSA: A New HADDOCK Scoring Function for Protein-Peptide Docking. Front. Mol. Biosci. 2016, 3, 1-13.

(98) Li, L.; Dunker, A. K.; Hsu, W.-L.; Meroueh, S. O.; Pilcher, M. N.; Liang, S.; Zhou, Y.; Uversky, V. Exploring the Molecular Design of Protein Interaction Sites with Molecular Dynamics Simulations and Free Energy Calculations. Biochemistry 2008, 48, 399-414.

(99) Wong, E. T. C.; Na, D.; Gsponer, J. On the Importance of Polar Interactions for Complexes Containing Intrinsically Disordered Proteins. PLoS Comput. Biol. 2013, 9.
(100) Li, Z.; Buck, M. Modified Potential Functions Result in Enhanced Predictions of a Protein Complex by All-Atom Molecular Dynamics Simulations, Confirming a Stepwise Association Process for Native Protein-Protein Interactions. J. Chem. Theory Comput. 2019, 15, 4318-4331.

(101) Saglam, A. S.; Chong, L. T. Protein-Protein Binding Pathways and Calculations of Rate Constants Using Fully-Continuous, Explicit-Solvent Simulations. Chem. Sci. 2019, 10, 2360-2372. 


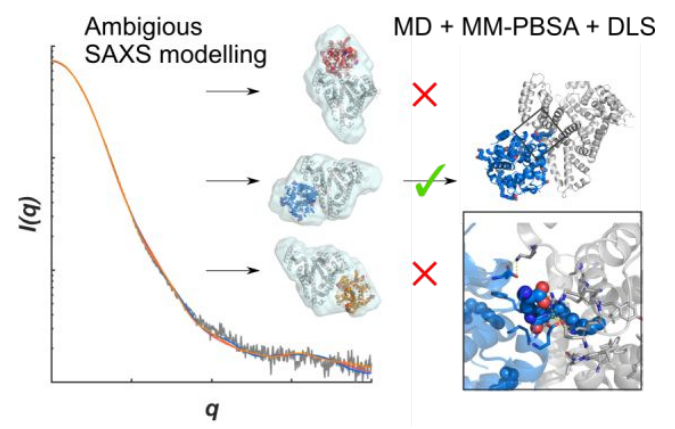

